\title{
LOS EFECTOS DE LA EXTINCIÓN DE LOS SALDOS INSOLUTOS EN EL CONCURSO SOBRE LAS GARANTÍAS OTORGADAS POR TERCEROS
}

\section{THE EFFECTS OF DISCHARGE OVER THIRD PARTY SECURITIES \\ Guillermo Caballero Germain* \\ Juan Luis Goldenberg Serrano**}

\section{RESUMEN}

El presente trabajo analiza los efectos del descargue sobre las garantías otorgadas por terceros a favor del deudor insolvente (garantías exógenas). La tesis defendida es que el descargue es un beneficio legal personalísimo otorgado al deudor insolvente, quien gozará de una excepción perentoria para oponerse frente al cobro de cualquier saldo insoluto de una obligación nacida con anterioridad al inicio del procedimiento concursal. Esa excepción, dado su carácter personal, no beneficia al tercero garante.

Palabras clave: procedimiento concursal; garantía exógena; descargue.

\section{AbSTRACT}

This paper analyzes the effects of the discharge over securities granted by third parties in favor of an insolvent debtor. The thesis we support is that discharge is a personal legal benefit granted to the insolvent debtor, who shall have a substantive defense in case any of its creditors intends to collect any balance of a pre-bankruptcy claim. Due to

*Abogado. Doctor en Derecho. Profesor de Derecho Comercial de la Universidad de Chile. Dirección postal: Pío Nono 1, Providencia, Región Metropolitana, Chile. Correo electrónico: gcaballero@derecho.uchile.cl

** Abogado. Doctor en Derecho por la Universidad de Salamanca. Profesor de Derecho privado en la Pontificia Universidad Católica de Chile. Dirección postal: Avenida Libertador Bernardo O’Higgins 34, Santiago, Región Metropolitana, Chile. Correo electrónico: jgoldenb@uc.cl

Recepción: 2020-07-23; aceptación: 2020-11-02. 
its personal nature, such defense does not benefit any third-party guarantor.

Keywords: Bankruptcy proceeding; third-party security; discharge.

\section{INTRODUCCIÓN}

La extinción de los saldos insolutos una vez firme la resolución de término de un procedimiento concursal de liquidación (descargue) ha sido objeto de atención tanto por la doctrina como por la jurisprudencia nacional a partir de la entrada en vigencia de la $L^{1}{ }^{1}$. En este trabajo nos interesa abordar las consecuencias del discharge respecto de las garantías constituidas por terceros a favor del deudor concursal ${ }^{2}$. El análisis de los efectos del descargue sobre las garantías exógenas propone un problema de coordinación entre dos sistemas de normas: el derecho concursal y el derecho civil. Esa coordinación debe operar desde la premisa de la preeminencia del derecho concursal como régimen especial por sobre el derecho común (arts. 4 y 13 del $C$ C). Sin embargo, al no pronunciarse expresamente la LC acerca de los efectos sobre las garantías exógenas, es necesario un esfuerzo ulterior por precisar cómo debe operar el acomodo del derecho común en coherencia con la lógica del derecho especial.

Para realizar esta coordinación es necesario tener presente que el $C C$ se construye sobre la base del rigor de la regla de responsabilidad patrimonial universal (art. 2465 del $C$ C), de tal suerte que la lectura conjunta de las normas civiles impide pensar en la ruptura total de la promesa del legislador que permite a los acreedores mantener sus posibilidades de cobro y persecución respecto a los bienes futuros del deudor hasta la completa extinción de la deuda ${ }^{3}$. En efecto, si seguimos la huella del concurso en el $C C$, en las reglas del pago con cesión de bienes y del beneficio de competencia, la insolvencia derivada de accidentes inevitables y la liquidación de todo el patrimonio embargable del deudor de buena fe solo permiten posponer el pago de la deuda hasta que mejore la fortuna del deudor, pero jamás podrían llevar a su extinción ${ }^{4}$.

${ }^{1}$ Véase, especialmente, Caballero (2017), (2018) y (2020); Goldenberg (2017) y (2020) y AlARCón (2018a) y (2018b).

${ }^{2}$ Debe tenerse en cuenta que, a pesar de que el proyecto presentado por el Poder Ejecutivo para modernizar los procedimientos concursales (Boletín 13802-03) pretende reformular ciertos aspectos muy relevantes del descargue de las deudas, no se refiere a la materia de este artículo.

${ }^{3}$ Goldenberg (2019), pp. 104-105.

${ }^{4}$ Goldenberg (2017), pp. 242-244. 
La extinción de los saldos insolutos una vez firme la resolución de liquidación rompe la promesa de la garantía general patrimonial del deudor insolvente respecto de los acreedores afectos al concurso, alterando sustancialmente el modelo del $C C$. Nuestra tesis es que el nuevo equilibrio entre los intereses en juego (deudor, acreedores y tercero garante) viene dado por no tratarse de una ruptura total de esa promesa, sino parcial: se quiebra únicamente respecto al deudor en concurso, a favor de quien se establece el descargue con carácter de personalísimo, sin poder extenderse a otros obligados en garantía. Esta fórmula fragmentada de articular los efectos del concurso en el derecho civil, distinguiendo entre el deudor concursado y los terceros garantes, es coherente con la utilizada por Andrés Bello en la hipótesis más cercana al desconocido descargue en nuestro $C C$ : la cesión de bienes y el beneficio de competencia. La coincidencia del supuesto de hecho (la insolvencia) y la protección del deudor por sobre los acreedores una vez que aquel hizo "abandono voluntario" de todos sus bienes acerca la antigua cesión de bienes a la contemporánea exoneración de los saldos insolutos. En ese contexto, la coordinación de la insolvencia con el régimen de las garantías se ordena en torno a la diversificación de los efectos de la cesión de bienes y el beneficio de competencia respecto a los distintos obligados; esto es, distinguiendo entre los efectos para el deudor y los terceros garantes ${ }^{5}$.

Esta aproximación bifronte frente al fenómeno de la insolvencia debe guiar el análisis de los efectos del descargue sobre las garantías exógenas, de forma de realizar una lectura armónica de las reglas concursales y civiles relacionadas con el problema en estudio. Esta lectura coordinada supone:

I) precisar los elementos característicos del descargue en nuestro ordenamiento, desde su reconocimiento hasta nuestros días,

II) la forma en que la legislación concursal aborda el tratamiento de las garantías exógenas en los distintos procedimientos concursales,

III) sobre cuya base podrá ensayarse una propuesta de coordinación del derecho común con el derecho concursal.

${ }^{5}$ Esta aproximación tiene un largo abolengo en el derecho occidental: "If a debtor became insolvent owing to misfortune, he was able to avoid the harshness of personal execution by way of cession bonorum, i.e. by ceding his property to the creditors. Once he had done that, he could bar further claims with the exception nisi bonis cesserit. Defenses of this kind, which were based on certain snags pertaining to the person of the main debtor, rather than the principal obligation, could not be raised by the fideiussor": ZimMERMANN (1996), p. 123. [Traducción de los autores: si un deudor devenía insolvente debido a su mala fortuna, era capaz de evitar la dureza de la ejecución personal mediante la cessio bonorum, es decir, cediendo sus bienes a los acreedores. Una vez hecho esto, podría inhibir otras acciones de cobro con la exceptio nisi bonis cesserit. Este tipo de defensas, que se basaban en ciertos inconvenientes relacionados con la persona del deudor principal, más que con la obligación principal, no podían ser invocadas por el garante]. 


\section{LA (DEFICIENTE) REGULACIÓN DEL DISCHARGE EN LA LEY CONCURSAL CHILENA}

\section{El origen y los antecedentes patrios del descargue ${ }^{6}$}

Las primeras noticias del discharge se encuentran en la Inglaterra de la reina Ana a inicios del siglo XVIII, curiosamente contextualizada en un sistema concursal casi puramente sancionatorio. Si analizamos el "Act to prevent frauds frequently committed by bankrupts" de 1705 [1706] (IV \& V, Anne, c. 17), podremos observar dicha dualidad: por una parte, la quiebra fraudulenta se entendió como una reacción ante el deudor reticente y falto de cooperación, y, como tal, expresaba todo su rigor hasta consagrar la penalidad de la muerte ${ }^{7} \mathrm{y}$, por la otra, se beneficiaba a quien cooperaba con la justicia, hasta eximirlo del pago de todas las deudas existentes al inicio del procedimiento ${ }^{8}$. De los comportamientos probos exigidos al deudor también se deduce que la regla tenía por objetivo la generación de una herramienta destinada a fortalecer la posición de los acreedores, utilizándola como un incentivo conducente al incremento de sus posibilidades de satisfacción ${ }^{9}$.

Pero no fue este el modelo que llegó a nuestras tierras, sino aquel que fue fruto de los reacomodos del discharge en Estados Unidos de América, país que tardó más de cien años en contar con una normativa concursal estable, dando cumplimiento a la denominada bankruptcy clause dispuesta en el ámbito constitucional ${ }^{10}$. Con continuos vaivenes, derivados especialmente del contexto económico, de las dudas morales y de los efectos que tenía el descargue en los índices de cobro de los acreedores (creditor oriented), esta pieza tuvo una finalidad diversa: incentivar los emprendimientos a pesar de los riesgos ínsitos de los negocios, en tiempos en los que la tipología societaria no se había ampliado lo suficiente para ofrecer limitaciones de responsabilidad para estructuras diversas a la sociedad anónima (debtor oriented). Solo con la Bankruptcy Act de 1898, el concurso se volvió fundamentalmente voluntario y el descargue de la deuda se

${ }^{6}$ Un análisis más acabado sobre este particular se encuentra disponible en GoLDENBERG (2020a), passim.

${ }^{7}$ KADENS (2010), p. 1231.

${ }^{8}$ Para un mayor detalle de estos requisitos, McCoId (1996), p. 167.

${ }^{9}$ De ahí los cambios legislativos que se fueron sucediendo en las reglas inglesas a efectos de requerir (o no) de la aprobación de los acreedores para su obtención (certificate of conformity). Véanse, 5, Anne, c. 22; 5\& 6, Victoria, c. 121; 12 \& 13, Victoria, c. 106; 32 \& 33, Victoria, c. 71; y 46 \& 47, Victoria, c. 239.

${ }^{10}$ Para una referencia a la incorporación del bankruptcy clause en la Constitución americana, NoEL (1919), pp. 67-123. 
obtenía previa solicitud del deudor al tribunal, en el plazo de un mes a partir de la adjudicación y hasta doce meses luego de ella, con la posibilidad de oposición de los interesados solo fundada en haber cometido un delito sancionado con la privación de libertad o actitudes fraudulentas que terminaban por perjudicar a los acreedores. También se limitaron las consecuencias del discharge a efectos de excluir créditos tributarios, por indemnizaciones de perjuicios o resultados de fraude, y se dispuso expresamente que la responsabilidad de los codeudores o garantes no sería alterada por el beneficio concedido al deudor concursado.

$\mathrm{Al}$ decir de Karen Gross, toda esta evolución da cuenta de cómo las sociedades se encuentran en una encrucijada al tiempo de determinar qué trato desean dar a sus deudores, anotando que, en general, se ha transitado desde aquella lógica que podía conducirle a la privación de libertad (o, incluso, la muerte) hacia una absolución en que el incumplimiento de las obligaciones, sea o no voluntario, es un hecho que debe ser simplemente olvidado ${ }^{11}$.

Fue en este estado de la discusión que la regla llegó a nuestras tierras. La influencia anglosajona en la formulación de la Ley n. ${ }^{\circ} 4558$, de 1929, parece evidente, aunque escasas constancias encontramos de ello en su Mensaje $^{12}$. Desde la perspectiva del discharge, su incorporación responde a los avances de la época, entendiendo la extinción de las deudas insolutas como un medio de tutela del deudor y ya no como un impulso a la cooperación en beneficio de los acreedores ${ }^{13}$, presentándose como una especie de "perdón legal" ${ }^{14}$ respecto al deudor de buena fe ${ }^{15}$. Mirando con mayor detalle la historia de la ley, se advierte que no se trató este de un

${ }^{11}$ Gross (1999), p. 92. El tránsito, eso sí, se ha dado principalmente por motivaciones económicas (aunque los autores no dejan de mencionar, incluso, referencias teológicas sobre la base del perdón, op. cit., p. 93), a fin de permitir el reingreso del deudor al círculo económico y su recalificación como sujeto digno de crédito.

${ }^{12}$ Este solo advertía la necesidad "de reformar la legislación mercantil vigente, para ponerla en armonía con las exigencias de la economía nacional y con la evolución del pensamiento jurídico en los últimos cincuenta años, que se ha acentuado vigorosamente después de la guerra europea de 1914". Sin embargo, ArCos (1929), p. 118, anota que el discharge "nos acerca al espíritu de las legislaciones anglo-sajonas, que consideran la quiebra como un estado fisiológico del cual se debe tratar de liberar al fallido en beneficio de él y de la colectividad". En el mismo sentido, Sandoval (2007), p. 204.

${ }^{13}$ Un punto en que se aprecia una distancia, sin embargo, es en la interpretación dada a la expresión "saldo insoluto". Durán (1935), p. 456 y Bravo (1940), pp. 90-91, sostenían que, en atención a la referencia a los saldos insolutos, la realización de los bienes en el concurso debía haber permitido un pago parcial de las deudas. En contra, PUGA (2004), p. 695, fundado que ello "no tiene coherencia con el principio sustentatorio de este resorte concursal y resulta extremadamente arbitrario".

${ }^{14}$ Carrasco Vásquez (1963), p. 118.

${ }^{15}$ Puga (2004), p. 687 y Gómez y Eyzaguirre (2011), p. 459. 
aspecto particularmente debatido. Lo anterior, tal vez porque esta nueva legislación fue tramitada con inusual premura. Así, terminó formulándose un "sobreseimiento definitivo extraordinario" que se caracterizaba por poner fin al estado de quiebra (art. 128), por no ser automático, sino que era necesario el transcurso de cinco años, contados desde que hubiere sido aprobada la cuenta general del síndico (art. 134, núm. 1) y requerir un actuar de buena fe, aludiendo al término del procedimiento de calificación de la quiebra del deudor comerciante, por sentencia ejecutoriada, en que la quiebra hubiese sido calificada de fortuita $y$, si se tratare de un deudor no comerciante, que no hubiese sido condenado por alguno de los delitos contemplados en el art. 466 del Código Penal (art. 134, núms. 2 y 3). Por su parte, no necesitando del consentimiento de los acreedores, solo se les concedía la posibilidad de oponerse a la solicitud de descargue, aunque sin enunciar las razones para ello, de lo que se deduce que solo podía referirse al incumplimiento de los requisitos legales. Exactamente el mismo sistema se propuso en el contexto de la Ley n.$^{\circ} 18175$, de 1982 , con la sola diferencia que el término de espera para la obtención del beneficio se limitó a solo dos años desde la aprobación de la cuenta del síndico (art. 165).

No obstante, si contrastamos la regulación patria con los antecedentes comparados que llevaron a la consagración del sobreseimiento definitivo extraordinario, no puede pasarse por alto que el régimen jamás fue completo ni implicó un trasplante íntegro de las regulaciones que presuponemos se tuvieron a la vista. Por una parte, la normativa omitía la existencia de algunas limitaciones legales, sin ofrecer, por ejemplo, un catálogo de obligaciones que por diversos motivos no podían ser extinguidas por estas vías ${ }^{16}$; y, por la otra, y es aquí donde nos queremos detener, nada se indicaba sobre los efectos de la extinción si existían codeudas solidarias o garantías otorgadas por terceros. Este segundo punto, que había sido preterido en la primera regulación del discharge en 1705 [1706] (IV \& V, Anne, c. 17), debió ser subsanado con rapidez en Inglaterra por medio de una ley complementaria de 1711 (X, Anne, c. 15), con referencia expresa a que la extinción no beneficiaba a los socios del deudor quebrado, ni a otros conjunta o solidariamente responsable de las deudas. Y, como tal, se integró en todas las normas anglosajonas que le siguieron y también, en Estados Unidos de América, de manera que el silencio en las leyes de quiebra chilenas parece haber sido más bien fruto de una desatención que un deseo de promover una respuesta diversa.

${ }^{16}$ A ello se sumaban las críticas por la falta de claridad respecto a las obligaciones condicionales, las resultantes de contratos de tracto sucesivo y las obligaciones no dinerarias. Sobre el particular, véase PUGA (2004), pp. 695-696. 


\section{El discharge en la Ley $n .^{\circ} 20720$}

La exoneración legal de las deudas insolutas aparece regulada en la LC en tres hipótesis: al término de un procedimiento concursal de renegociación en virtud de un acuerdo de ejecución (art. 268.II); una vez firme la resolución de término en un procedimiento concursal de liquidación de una empresa deudora (art. 255) y, por remisión normativa, también al término de un procedimiento concursal de liquidación de una persona deudora (art. 281). Para estas últimas, el régimen legal se establece en los términos siguientes:

"Una vez que se encuentre firme o ejecutoriada la resolución que declara el término del Procedimiento Concursal de Liquidación, se entenderán extinguidos por el solo ministerio de la ley y para todos los efectos legales los saldos insolutos de las obligaciones contraídas por el Deudor con anterioridad al inicio del Procedimiento Concursal de Liquidación"17.

Las novedades respecto a la regulación previa son sustanciales. El descargue opera ipso facto una vez ejecutoriada la resolución de término, sin tiempos de espera para su obtención, desapareciendo, asimismo, la exigencia de una conducta honesta del deudor. En suma, basta que la resolución de término adquiera firmeza para que el deudor obtenga el beneficio de la exoneración legal de los saldos insolutos de todas las obligaciones previas a la dictación de la resolución de liquidación.

La peculiar configuración del descargue en la LC ha tenido un significativo impacto en el funcionamiento y comprensión de los procedimientos concursales de liquidación por ella instaurados. La generosidad y rapidez con que se otorga al deudor el descargue ofrece al deudor un poderoso incentivo para iniciar de forma voluntaria un procedimiento concursal de liquidación ${ }^{18}$. Lo anterior aparece en contradicción con la cuestionada preferencia de los redactores de la LC por la reorganización (o la renegociación) como mecanismo para resolver la insolvencia por sobre la liquidación concursal, según se desprende de la historia de la ley ${ }^{19}$. Las estadísticas oficiales muestran que, contrariamente a la preferencia del diseño legal, el procedimiento más utilizado es la liquidación concursal:

${ }^{17}$ Art. 255.I de la LC.

${ }^{18}$ Ese incentivo no ha sido desatendido por la "industria" de los servicios legales, que ha publicitado y fomentado el uso del descargue, en una dudosa conducta desde el punto de vista ético.

${ }^{19}$ Historia de la LC, p. 7 (Mensaje) y p. 2244. En este sentido, Puga (2016), p. 61. 
el año 2019, se iniciaron 4542 procedimientos concursales de liquidación de la persona deudora y solamente 1274 de renegociación. En cuanto a las empresas deudoras, se iniciaron cuarenta y seis procedimientos concursales de reorganización, frente a 1588 de liquidación ${ }^{20}$.

Más allá de las estadísticas, la facilidad con que un deudor puede obtener el descargue de sus deudas ha generado la impresión de ser los procedimientos concursales instrumentos que permiten un uso abusivo por parte de algunos deudores ${ }^{21}$. Conviene en este punto ser cautos. $\mathrm{Si}$ bien es cierto que la regla de descargue presenta serias deficiencias, es importante destacar que el hecho de contar el deudor (especialmente, consumidor) con un exiguo patrimonio con relación a sus deudas, no debe considerarse como un ejercicio per se abusivo del procedimiento concursal de liquidación y equipararse a la mala fe, como lo demuestra la tendencia en otras legislaciones a establecer reglas especiales (zero plans) para aquellos deudores de buena fe sin activos ni ingresos (no income, no assets), destinadas a protegerlos y no a castigarlos ${ }^{22}$. Las razones por las cuales una persona se endeuda (o sobreendeuda) son variadas e, incluyen, en nuestro país el pago de servicios de salud o educacionales, y, en caso más extremos, incluso para la satisfacción de otras necesidades básicas, como la alimentación ${ }^{23}$. A su turno, las causas de la insolvencia de un consumidor, mayoritariamente responden a factores ajenos a su control (desempleo, divorcio, enfermedad) ${ }^{24}$. Por lo anterior, el descargue constituye una herramienta útil para aliviar el creciente sobreendeudamiento de un importante sector de la población, al permitir al deudor (volver a) insertarse en el tejido productivo, quien, de otra forma, debería soportar ese agobio por largo tiempo. Por ello, la escasez de bienes del deudor no debe impedir per se la concesión del descargue, ni identificarse con la mala fe del deudor.

Con todo, la ruptura operada por la LC de la tradicional fisonomía del descargue es problemática, desde varios puntos de vista. Por una parte, se desgaja de la tradición patria y del estándar internacional que concede este

${ }^{20}$ www.superir.gob.cl/wp-content/uploads/2019/12/Bolet $\%$ C3\%ADn-Estad $\%$ C3\%ADstico-Mensual-14-diciembre-2019.pdf [fecha de consulta: 9 de mayo de 2020].

21 "Eso, creemos, se ha dado como consecuencia de un uso indebido o, derechamente, un 'abuso' de las personas sobre la LC, para efectos de extinguir sus obligaciones para con terceros, sin liquidar casi ningún activo”, columna de Tomás Contreras, El Mercurio Legal, martes 31 de julio de 2020.

${ }^{22}$ Caballero (2018), p. 142, con ulteriores referencias.

${ }^{23}$ Véase la Encuesta Financiera de Hogares del Banco Central de Chile, 2017, disponible en www.bcentral.cl/web/banco-central/areas/encuestas-economicas [fecha de consulta: 15 de septiembre de 2020].

${ }^{24}$ Para una referencia a la clasificación del sobreendeudamiento en razón de sus causas, véase Goldenberg (2020b), p. 3. 
beneficio legal solamente a los deudores honestos, pero desafortunados ${ }^{25}$. Por otra parte, repitiendo la omisión de la legislación previa, falta un listado de créditos inmunes al descargue, como, por ejemplo, las deudas de alimentos (y, en general, de familia) ${ }^{26}$, las multas o los créditos derivados de la responsabilidad extracontractual ${ }^{27}$.

Como adelantamos, en el presente trabajo nos interesa analizar otro problema derivado de la escueta regulación del descargue en nuestro ordenamiento. La referida regla no se pronuncia acerca del efecto de la exoneración legal de los saldos insolutos sobre las garantías constituidas por terceros para caucionar el cumplimiento de las obligaciones del deudor, ahora, insolvente. Si bien la legislación previa sobre el descargue tampoco contemplaba una regla expresa sobre las garantías otorgadas por terceros, las radicales diferencias con la regla de descargue actual (más generosa en sus efectos y breve en sus plazos) han significado que los problemas derivados de esta omisión dejen de ser una cuestión teórica (por lo inusual) para convertirse en un problema frecuente, de gran relevancia práctica, para cuyo análisis es útil referirnos previamente al tratamiento general de las garantías exógenas en la LC, a lo cual dedicamos la sección siguiente.

${ }^{25} \mathrm{El}$ hecho de operar el descargue de forma automática una vez firme la resolución de término, dificulta encontrar la oportunidad procesal idónea para morigerar los efectos de una regla de descargue en exceso generosa por la vía de la aplicación en sede concursal del principio general de la buena fe. Probablemente por esa razón, los tribunales de primera instancia han endurecido los requisitos de admisibilidad de las demandas de inicio de un procedimiento concursal de liquidación voluntaria, tras el cual, el descargue aparece como una consecuencia inevitable. Para más antecedentes sobre los problemas de la actual configuración de la regla de descargue y sus posibles soluciones, reenviamos a CABALLERO (2018), especialmente, pp. 150-165.

${ }^{26}$ Aunque algunos de estos problemas pueden ser resueltos por medio del recurso a la integración de tratados internacionales, como los que formulan el principio de protección del interés superior del menor (Convención sobre los Derechos del Niño, ratificada en Chile por el Decreto 830, de 27 de septiembre de 1990).

${ }^{27}$ Esta grave omisión de la regla actual ha dado lugar a una reacción, tanto administrativa como judicial, a fin de limitar el descargue sobre algunas deudas (art. $2^{\circ} .3$ del oficio circular superior n. ${ }^{\circ}$ 5, de 19 de mayo de 2020). En el ámbito judicial, la Primera Sala de la Corte Suprema ha declarado en varias sentencias (por ejemplo, rol n. ${ }^{\circ} 14311$ 2019) que quedan excluidos de los procedimientos concursales regulados en la LC y, por consiguiente, del descargue, los denominados “créditos CAE" al estar regulados por una ley concursal especial (la Ley n. ${ }^{\circ}$ 20027, sobre financiamiento de los estudios de educación superior). Sin embargo, recientemente, la Tercera Sala de la Corte Suprema ha puesto en duda esta doctrina (rol n. $\left.{ }^{\circ} 59567-2020\right)$. El punto ha concitado el interés de la doctrina: CABALlero (2017) y (2020) y Alarcón (2018a). Sin perjuicio de la crítica que ha recibido esta jurisprudencia, lo que aquí interesa es destacar que la actual legislación carece de límites explícitos a la tutela ofrecida al deudor insolvente a través del descargue, a diferencia de lo que se observa en el derecho comparado. 


\section{LAS GARANTÍAS EXÓGENAS \\ EN LA Ley Concursal CHILENA}

\section{Consideraciones generales}

Es usual la indicación de que el concurso constituye un test de eficacia de los derechos de garantía ${ }^{28}$. Lo anterior alude a verificar si acaso el inicio de los procedimientos concursales afecta el régimen normal de una garantía o, al contrario, conserva su vigor como medio de asegurar el cumplimiento de la obligación principal. Son múltiples los factores que inciden en ello, muchos de los cuales solo pueden ser explicados a la luz de la necesaria alteración derivada de los propósitos de eficacia colectiva o los fines internos del concurso y, otros, en la finalidad de evitar comportamientos estratégicos de los acreedores, sea para restar o incrementar su valor y posibilidad de recuperación habida cuenta de las consecuencias que provoca un tratamiento diferente en el contexto de la ejecución individual ${ }^{29}$. A continuación, nos interesa revisar someramente el régimen jurídico de las garantías en los diversos procedimientos previstos en la LC, con especial foco en las de carácter exógeno, de manera de verificar la forma en que la regla concursal afecta o no su régimen general, todo ello a fin de poder colegir ciertos principios que ayuden a comprender las consecuencias que en ellas provoca el discharge.

Antes de analizar la escueta regulación de la LC sobre las garantías exógenas, cabe precisar algunos de sus rasgos. Si atendemos a las garantías personales (solidaridad pasiva, fianza, aval) ${ }^{30}$, ellas siempre son externas, de manera tal que el resguardo adicional que confieren consiste en la posibilidad de que el acreedor pueda dirigirse en contra del patrimonio de un tercero para la solución total (o limitada) de la deuda. En cambio, si atendemos a las garantías reales (prenda o hipoteca) ${ }^{31}$ el elemento de ajenidad no siempre está ínsito en su estructura, pudiendo ser otorgada por el propio deudor (a efectos de facilitar los medios de ejecución y conceder los derechos de preferencia y persecución) o por terceros, caso en el

${ }^{28}$ Carrasco Perera (2008), p. 44.

${ }^{29}$ En el contexto americano, esta idea ha pasado a denominarse el Butner principle, que no es más que el ideal de respeto, salvo supuestos excepciones contemplados legalmente, de las relaciones jurídicas preexistentes. Sobre este particular, véase JACKSON (1986), pp. 21-23.

${ }^{30}$ Art. 1511 y ss. y 2335 del $C C$, y art. 46 de la Ley n. ${ }^{\circ} 18092$. La solidaridad pasiva no necesariamente constituye una garantía personal en términos técnicos, tanto porque su origen no siempre es convencional, como, asimismo, porque tal calidad solo se revela en la medida en que la obligación sea contraída por personas que no tienen interés en la deuda, como se aprecia en el art. 1522 del $C C$. En este sentido, Somarriva (1943), p. 39.

${ }^{31}$ Arts. 2388 y 2414 del $C C$, y art. $1^{\circ}$ del art. 14 de la Ley n. ${ }^{\circ} 20190$. 
cual se suma a la posibilidad de ejecutar un bien que no forma parte del patrimonio del deudor y, por tanto, ajeno a la responsabilidad universal del art. 2465 del $C C$.

\section{Las garantías en el procedimiento concursal de reorganización}

La regulación dispuesta en el libro IV del Código de Comercio establecía la figura del convenio judicial como un acuerdo en que solo podían participar los acreedores valistas, como una forma de asegurar la tutela preferencial de los demás créditos ${ }^{32}$. Sin embargo, esta decisión conllevaba un importante obstáculo para la reorganización de la empresa si existían preferencias especiales sobre bienes esenciales para la continuidad de la actividad ${ }^{33}$. A fin de fortalecer la posibilidad de rescate de la empresa viable, la LC dispone que el acuerdo de reorganización debe incluir ahora a acreedores valistas, hipotecarios y prendarios, aun cuando se admite la posibilidad de separar su tratamiento en clases (art. 79). El régimen, por tanto, dependerá de si se ha producido o no tal división y de la integración de los créditos en una u otra categoría (art. 78), de acuerdo con el valor de liquidación del activo gravado y el importe del crédito ${ }^{34}$.

En caso de que se trate de un bien calificado como esencial, resulta indudable que el acreedor garantizado será parte del acuerdo de reorganización y que, en consecuencia, le serán oponibles sus términos. En tal sentido creemos debe interpretarse el art. 95, núm. 1, con independencia de si el bien objeto de la garantía sea de propiedad del deudor o de un tercero $^{35}$.

Por su parte, en caso de que el bien sobre el cual recae la garantía haya sido declarado como no esencial para la continuidad del giro, la ley ofrece una nueva distinción, dependiendo si aquel pertenece al deudor

${ }^{32}$ Puga (2014), pp. 289-291.

${ }^{33}$ En este sentido, Historia de la LC (Mensaje, p. 9), siguiendo la sugerencia en este punto de la Guía Legislativa sobre el Régimen de la Insolvencia de la CNUDMI. En este sentido, Contador y Palacios (2015), pp. 124-125.

${ }^{34}$ JeQuier Lehuedé (2015), p. 411 y (2016), pp. 34-35. Este criterio ha sido criticado puesto que "en la práctica, el valor de liquidación de los bienes muebles prendados es sustancialmente inferior al de los inmuebles hipotecados”, PugA (2014), p. 208.

${ }^{35}$ Con ello, sin embargo, se produce un desajuste conceptual para el caso en que la garantía fuese exógena, toda vez que, respecto a la empresa deudora, se trata éste de un crédito valista, pero, para fines de votación y efectos del acuerdo de reorganización, se le tratará como crédito garantizado, del mismo modo que las prendas e hipotecas constituidas por el propio deudor. En general sobre este punto, JEQUiER (2016), p. 42, y sobre algunos problemas que genera esta regla, PugA (2014), pp. 296-298. 
o a un tercero ${ }^{36}$. Nos centraremos, en el supuesto de la garantía exógena (art. 95, núm. 3), en que se otorga al acreedor garantizado una opción, que se replica para el caso de las garantías personales (art. 95, núm. 4). Si estima que el acuerdo le dejará en una mejor posición de cobro y, por tanto, vota favorablemente el mismo, se sujetará de forma íntegra a sus disposiciones y no podrá perseguir su crédito en términos diferentes a los estipulados ${ }^{37}$. En caso de manifestar su intención de no votar o no asista a la junta de acreedores, su crédito no se considerará en el pasivo con derecho a voto, y podrá cobrar su crédito respecto de las garantías constituidas por terceros.

En este último caso, el fiador, el codeudor, el avalista, el tercero poseedor de la finca hipotecada o propietario del bien prendado que hubiere pagado, podrá ejercer su derecho de subrogación o reembolso mediante un procedimiento incidental, solicitando que el acuerdo se cumpla a su favor (art. 95, inciso final). Pero, como podrá observarse, la acción de regreso del tercero garante se verá afectada por los términos de un acuerdo de reorganización en el que ni él ni el acreedor subrogado participó, de modo que el único modo de entender esta solución es que ella haya sido impuesta por el legislador para asegurar la viabilidad del negocio mediante la ultraactividad de sus efectos ${ }^{38}$. En efecto, si acaso el tercero garante hubiese podido exigir el cumplimiento de los créditos en los términos originales, que, incluso, son los que él debió haber solventado voluntaria o involuntariamente, podría poner en riesgo el equilibrio económico del acuerdo de reorganización.

De todo lo anterior es posible extraer dos ideas relevantes para nuestro estudio. La primera es que los derechos del tercero garante serán restringidos a consecuencia del procedimiento concursal del deudor principal. En circunstancias normales, una garantía exógena opera de forma que la "incidencia definitiva de las consecuencias de su cumplimiento recaiga en una esfera ulterior, diversa a la del propio garante" (causa cauendi) ${ }^{39}$. Sin

${ }^{36}$ Cuyas razones no quedan del todo claras de la lectura de la ley y su historia legislativa. En este sentido, Araya y Bofill (2013), p. 322.

${ }^{37}$ La norma no indica qué ocurre en caso de que el acreedor vote en contra del acuerdo de reorganización. Creemos que lo anterior se debe a una asunción errónea del legislador, en el sentido de entender que si el acreedor vota en contra no se logrará el quórum de aprobación, lo que, en todo caso, dependerá de la conformación del pasivo. Ante tal silencio, nos parece que una votación en contra igualmente implica el deseo del acreedor de formar parte de la voluntad colegial, por lo que termina asumiendo los resultados de la votación. De este modo, si a pesar de su voto negativo se logra el quórum de aprobación, entendemos que los efectos jurídicos son los mismos que aquellos que describe la ley para el voto favorable.

${ }^{38}$ JEQUIER (2016), p. 42.

${ }^{39}$ Fernández (2009), p. 86. 
embargo, dado que el tercero garante ha tomado sobre sí los riesgos de la insolvencia, debe soportar sus consecuencias. La segunda es la constatación de que no forma parte del espíritu de la LC beneficiar la posición de los garantes cuando el deudor principal está concursado, respetando la idea de que una de las finalidades de las cauciones consiste precisamente en dar resguardos frente al riesgo de insolvencia, en especial cuando ella no afecta al tercero.

\section{Procedimiento concursal de renegociación}

En este tipo de procedimiento, las reglas se bifurcan en la situación del acreedor garantizado en el contexto de la audiencia de renegociación y de ejecución. En la primera, el art. 266 de la LC exige que, para ser aprobado, el acuerdo de renegociación cuente con la aceptación de la persona deudora y de dos o más acreedores que, en su conjunto, representen más del 50\% del pasivo reconocido, pero descontando los créditos de los acreedores garantizados que asistan y voten en contra del acuerdo de renegociación propuesto.

En el caso de las cauciones personales, la regla diferencia según la actitud del acreedor garantizado, disponiendo que, en cualquier caso, cuando este concurre a la audiencia de renegociación y emite su voto negativo al acuerdo propuesto, su crédito no se considerará en el pasivo referido para efectos del quorum de aprobación. Lo anterior se justifica porque, como señala la norma a renglón seguido, este acreedor podrá perseguir el crédito respecto de los fiadores, avalistas o codeudores solidarios o subsidiarios, en los términos pactados al inicio. Ahora bien, creemos que, aunque la normativa no lo indica de modo expreso, esta circunstancia también implica que el acreedor ya no podrá dirigirse directamente en contra del patrimonio del deudor para efectos de lograr el pago de su acreencia y, en consecuencia, solo conservará sus acciones para dirigirse respecto al tercero garante. Puede sostenerse, incluso, que, en caso de tratarse de un fiador, no procederá el beneficio de excusión (arts. 2357 y ss del $C C)^{40}$, precisamente porque el acreedor garantizado ya no puede dirigirse en contra del deudor principal. La situación del garante es crítica: aun cuando pague la deuda, la acción subrogatoria o la acción de reembolso, en su caso, serán afectadas por el acuerdo de renegociación, replicando la respuesta dada en el campo del procedimiento concursal de reorganización (art. 95).

En el caso de las garantías reales, la regla distingue según si la garantía fue otorgada por el deudor o por un tercero. De nuevo, nos centraremos en el caso de las garantías exógenas (art. 266.VI). En este caso, si el acree-

${ }^{40}$ Corral (2016), p. 133. 
dor asiste y vota en contra del acuerdo de renegociación propuesto, su crédito no se considerará en el pasivo, de manera que no se computará para los efectos del quorum. En consecuencia, el acreedor garantizado podrá ejecutar las correspondientes prendas e hipotecas conforme a las reglas generales. Si acaso el tercero poseedor de la finca hipotecada o el propietario del bien prendado hubiere pagado la obligación garantizada (como indica Gonzalo Ruz Lártiga, "por el interés de mantenerse en posesión o conservar el dominio de la cosa" ${ }^{41}$, su situación es igualmente crítica, en cuanto su acción de subrogación se encontrará otra vez limitada, debiendo ajustarse a los términos del acuerdo de renegociación aprobado $^{42}$. En todo caso, cabe advertir que, en los supuestos de créditos garantizados, sean por cauciones personales o reales y, en este último caso, con indiferencia a si ellas han sido otorgadas por el deudor o por terceros, siempre serán considerados en el cómputo del pasivo para efectos de aprobación del acuerdo de renegociación, en caso de que el respectivo acreedor vote a favor del acuerdo o no asista a la audiencia ${ }^{43}$. Ahora bien, cabe preguntarse si acaso dicha aprobación tiene algún efecto respecto a

${ }^{41}$ Ruz (2017), p. 557.

${ }^{42}$ Un punto a resolver es si, en caso de votar en contra del acuerdo en todos los supuestos antes indicados, el acuerdo de renegociación es oponible o no a tales acreedores. Gonzalo Ruz Lártiga opina afirmativamente, entendiendo que la exclusión del crédito del pasivo no sería real, sino virtual, indicando: "el fin de la exclusión es permitir que los demás acreedores puedan acordarse con el deudor sobre la forma de solucionar sus acreencias, y ello se hace, en principio, sin perjudicar a los acreedores garantizados, que mantienen intactos sus derechos de realizar las garantías en los términos originales. Más claro aún, la pretensión del legislador fue evitar que el voto en contra del acreedor garantizado (generalmente un porcentaje considerable del pasivo) frustrare el procedimiento y la posibilidad de arribar a acuerdos con los demás”: op. cit., pp. 557-558. Si bien coincidimos con dicha finalidad, opinamos en sentido contrario. Creemos que, para estos acreedores, los términos del acuerdo de renegociación son por completo inoponibles, aunque restringido a los créditos que gozan de la garantía en cuestión. Ello es lo que justifica con exactitud que puedan ejecutarlas en los términos originalmente establecidos. En el caso en que el acreedor goce de otros créditos, estos, sin duda, no se encontrarán en los supuestos típicos antes referidos, por lo que, de ser aprobado el acuerdo, se sujetarán a sus términos y condiciones. En consecuencia, la inoponibilidad no se produce en relación con la persona del acreedor, sino del crédito garantizado.

${ }^{43} \mathrm{El}$ primer caso es evidente, puesto que ha manifestado de forma explícita la intención de formar parte del mismo. El segundo es más discutible, articulándose como una forma de ficción de una aprobación no realizada, pero que tiene por evidente finalidad propender a que el mentado acreedor tenga un incentivo real de participar, al menos, en la deliberación a la que se lleva a cabo en el marco de la audiencia en estudio. En ambos casos, el crédito se sujetará a los términos y modalidades establecidos en el acuerdo de renegociación aprobado, sin poder cobrarlo en términos o condiciones distintas a las estipuladas. Como indica Ruz (2017), p. 556, "el acreedor en este caso renuncia a cobrar su crédito extra concursus". 
las garantías otorgadas. En el caso de tratarse de cauciones reales, a menos que se haya indicado algo diverso en el contenido del acuerdo, nos parece que ellas persisten, salvo en el caso de remisión total o de novación, a menos que, en este último supuesto, se haya efectuado una reserva en los términos del art. 1642 del $C C$. En el caso de las cauciones personales, la regla a considerar es la del art. 1645 del $C C$, en la medida en que la novación liberta a los codeudores solidarios o subsidiarios que no han accedido a ella.

En caso de que no se acordare la renegociación y procediere la citación a la audiencia de ejecución, las reglas son diversas en lo que se refiere al tratamiento de las garantías, puesto que en este estado del procedimiento ya no es admisible que sus titulares se excluyan del acuerdo (en caso de ser aprobado) para efectos de la ejecución. En consecuencia, estos siempre concurrirán a la formación del quorum, tanto en lo que refiere al número como a su participación en el pasivo, sin que tenga influencia lo ocurrido en el eventual caso que se haya conformado el quorum de modo diverso en la audiencia de renegociación que rechazó el acuerdo. Lo anterior tiene sentido respecto a las garantías otorgadas por el propio deudor, puesto que, en el supuesto de la ejecución, los pagos se efectuarán de conformidad a las normas de prelación de créditos (art. 267 de la LC), respetando, en definitiva, la preferencia que le conceden la prenda o la hipoteca. Pero menor lógica tendría respecto de las garantías exógenas, puesto que, en tal caso, los créditos calificarán como valistas desde la perspectiva del pasivo del deudor. De lo anterior, nos parece que la aprobación del acuerdo de ejecución en nada puede limitar el ejercicio de las acciones de cobro respecto al tercero garante.

\section{Procedimiento concursal de liquidación}

En el contexto del procedimiento concursal de liquidación, no encontramos disposiciones que se refieran a la situación de las garantías exógenas de carácter real. Las reglas relativas a la suspensión de las ejecuciones, con exclusión de las que puedan acometer acreedores prendarios e hipotecarios (art. 135), solo tienen sentido en la medida en que el bien gravado sea de propiedad del propio deudor, puesto que responden a la idea de la universalidad objetiva derivada de la aplicación colectiva de la regla de la responsabilidad patrimonial universal (art. 2465 del $C C)^{44}$.

${ }^{44}$ Loreto Ried Undurraga con Gonzalo Baeza Ovalle (2012). Otro tanto ocurre en lo que se refiere a los regímenes excepcionales al interior del mismo procedimiento. Así, en el caso de la venta como unidad económica, el acuerdo no puede incluir bienes de propiedad de terceros (ni aún si son objeto de garantías o son esenciales para la conformación de 
No obstante, deberá recordarse que los bienes gravados de propiedad de terceros no integran la masa activa del concurso, puesto que ella solo incluye aquellos que son de dominio del deudor (art. 130 y ss. de la LC), por lo que difícilmente podría admitirse que bienes de terceros pasen a la administración diferenciada en los términos del art. 234 de la LC.

Sin embargo, sí encontramos algunas referencias en lo que respecta a las garantías personales. En efecto, el art. 117, núm. 1 de la LC, impide a los acreedores demandar la liquidación de la empresa deudora fundada en la cesación en el pago de una obligación que conste en título ejecutivo si acaso ella proviene de una fianza, codeuda solidaria o subsidiaria o de un aval. Aunque la pretensión de la regla parece encontrarse en construir este hecho revelador solo a partir de las deudas directas ${ }^{45}$, la justificación se tensiona en el caso de la codeuda solidaria, donde solo en la relación interna (contribución a la deuda) podrían efectuarse este tipo de distinciones fundadas en el interés al que alude el art. 1522 del $C C$. Una segunda referencia la encontramos en el art. 146 de la LC, donde se precisa que, respecto de las ejecuciones iniciadas antes de la dictación de la resolución de liquidación, la acumulación general dispuesta en el art. 142 y ss. de la LC solo se refiere al deudor y no a otros obligados al pago. En efecto, la regla advierte que el tribunal que está conociendo de dicho procedimiento lo debe suspender solo respecto al deudor concursado, remitiendo al tribunal que conoce el concurso copias autorizadas del expediente para continuar en este la sustanciación respecto del deudor, pero deberá conservar el expediente original a fin de continuar la ejecución respecto al resto de los demandados ${ }^{46}$.

dicha unidad), sino que solo puede comprender los activos deudor y los derechos que este tenga en un bien raíz ajeno -art. 217 de la LC, cuya formulación presenta algunos problemas, véase Ruz (2017), pp. 1088 y 1089-. De este modo, la excepción al art. 135 de la LC dada por la suspensión de los derechos de los acreedores hipotecarios, prendarios y retencionarios para iniciar o proseguir sus ejecuciones (art. 218 de la LC), solo puede referirse a los casos en que dichas garantías recaen sobre bienes que, integrando la unidad económica, forman parte de la masa activa del concurso. Igual ocurre en el supuesto de la continuación de las actividades económicas del deudor, aun cuando la regla del art. 233 de la LC no está redactada de manera tan clara como en el caso anterior, sin hacer referencia a la propiedad de los bienes adscritos a la continuación.

${ }^{45}$ En este sentido, CABALLERO (2015), p. 147, con ulteriores referencias. Una explicación en este sentido es ofrecida por ContAdor y PALACios (2015), pp. 162-163, indicando que la justificación de la regla se encuentra en evitar "la producción de excesos que transformen a la anterior quiebra en una mera cobranza judicial".

${ }^{46}$ Conforme se expresa en la historia de la norma, la Superintendenta de Quiebras, Josefina Montenegro, señaló lo siguiente: "se permite al acreedor continuar sus ejecuciones contra los codeudores, sin perjuicio de verificar su crédito en la liquidación del deudor principal. Hizo presente que se trata de juicios ejecutivos de obligaciones que constan en títulos ejecutivos, de dinero, líquidas y actualmente exigibles. Precisó que la sentencia respecto 
Como apreciamos, ambas reglas proponen un diferente destino de la obligación caucionada y las garantías, fundado en el hecho de que al menos en el caso de estas garantías personales, estamos frente a créditos que tienen una cierta independencia y que, por tanto, su destino queda sujeto a la situación patrimonial de cada uno de sus deudores. Este tratamiento diferenciado también debe considerarse, si se quiere una respuesta coherente, al analizarse el efecto del descargue sobre las garantías exógenas.

\section{LOS EFECTOS DEL DESCARGUE SOBRE LAS GARANTÍAS EXÓGENAS}

\section{La discusión jurisprudencial (antigua y nueva) sobre el efecto del descargue en las garantías exógenas}

Analizada la fisonomía de la regla de descargue (I) y el tratamiento de las garantías exógenas en los procedimientos concursales (II), corresponde ahora tratar derechamente los efectos del descargue sobre las garantías exógenas, para lo cual es útil tomar como punto de partida el análisis de la forma cómo la jurisprudencia se ha pronunciado sobre la cuestión antes (1.1) y después (1.2) de la entrada en vigencia de la Ley n. ${ }^{\circ} 20720$.

\subsection{La jurisprudencia previa a la Ley $n .{ }^{0} 20720$}

Como antes indicamos, si bien el denominado "sobreseimiento definitivo extraordinario" de la quiebra contenía una regla de descargue, no establecía expresamente el destino de las garantías exógenas una vez decretado. Durante los más de ochenta años de vigencia de la regla (casi sin variaciones), el efecto de la exoneración legal de los saldos insolutos al término de la quiebra fue (hasta donde tenemos noticias) motivo de un solo pleito. En la referida sentencia, la Corte Suprema, por voto de mayoría, sostuvo ${ }^{47}$ :

" 4 . Que, de acuerdo a lo que se ha consignado precedentemente, resulta inconcuso que en el juicio ejecutivo de autos, si bien cuando se inició existía una obligación que reunía las características que ordena la ley, con posterioridad ha sobrevenido un hecho que ha

de los demás ejecutados no debería ser contradictoria respecto del deudor principal, el que está sujeto a un procedimiento de liquidación, y en el improbable evento que lo sea, se podrá alegar judicialmente de acuerdo a las reglas generales, criterio que no compartió el profesor señor Puga, respaldándose en el efecto relativo de las sentencias": Historia de la LC, p. 2116.

${ }^{47}$ Banco de Concepción con Manuel Arredondo Bravo y otro (1992), pp. 95-97. 
extinguido tal obligación, cual es, el sobreseimiento definitivo de la quiebra de la deudora principal el que produce, como uno de sus efectos, la extinción de las obligaciones del fallido por los saldos insolutos de sus deudas anteriores a la declaración de quiebra, cuyo es el caso de autos;

$5^{\circ}$. Que lo concluido en el motivo anterior, no se desvirtúa por el hecho de referirse el artículo 165 de la Ley de Quiebras a las obligaciones del fallido, por cuanto la obligación contraída es una sola, de manera que si ésta se ha extinguido frente al deudor principal, por ordenarlo así la ley, no puede considerarse que subsiste para los fiadores y codeudores solidarios".

\subsection{La jurisprudencia posterior a la Ley n. ${ }^{\circ} 20720$}

En los casi seis años de vigencia de la actual ley concursal, se han producido varios pleitos sobre el efecto del descargue sobre las garantías exógenas, aunque la Corte Suprema no se ha pronunciado hasta la fecha sobre el asunto ${ }^{48}$.

La Corte de Apelaciones de Santiago se pronunció específicamente respecto del efecto del descargue sobre las garantías exógenas al conocer de tres recursos de apelación resueltos por una misma sala en los términos siguientes ${ }^{49}$ :

"Segundo: Que teniendo en cuenta lo antes dicho [que la controversia relativa al exacto alcance que debe darse a la norma contenida en el artículo 255 de la Ley 20.720, debe ser dirimida teniendo en consideración no sólo el tenor literal de la norma], es que debe determinarse si tal norma tiene el carácter de absoluta, en términos que cierre toda posibilidad de obtener el pago de las deudas en los bienes de quienes de manera personal y con garantías reales, se convierten en avales y codeudores solidarios del insolvente. Es

${ }^{48}$ En Rabobank Chile con Río Teno S.A. y otros (2019c), la Primera Sala de la E. Corte Suprema declaró inadmisible el recurso de casación en el fondo presentado por la ejecutada en contra de la sentencia de la Corte de Apelaciones, que rechazó el incidente en que se solicitaba declarar la extinción de la obligación ejecutada.

${ }^{49} \mathrm{Si}$ bien las causas estaban relacionadas entre ellas, la Corte de Apelaciones de Santiago consideró que no se cumplían los presupuestos para la acumulación de los recursos, no obstante lo cual decretó: "por motivos de economía procesal y certeza jurídica, procédase a la vista [...], uno en pos del otro, a contar del más antiguo, debiendo entregarse oportunamente a la tabla de un mismo relator": Rabobank Chile con Río Teno S.A. y otros (2019a), f. 320. En cumplimiento de esta resolución, la misma sala de la Corte conoció las apelaciones interpuestas en tres causas: Rabobank Chile con Río Teno S.A. y otros (2019a), Rabobank Chile S.A. con Río Teno S.A. (2019b) y Herman con Rabobank (2019). 
decir, si éstos pueden valerse de un hecho que atañe sólo al deudor, como lo es su situación patrimonial en crisis, para convertirlo en un verdadero beneficio en su favor, como lo es el liberarse de las obligaciones que contrajeron al constituirse como tales.

Es obvio que lo hicieron para el caso que el deudor principal no pague, que es lo acontecido, surgiendo así su obligación de hacerlo toda vez que deben responder en igual forma, no siendo posible aceptar una distinción que en los hechos al momento de contraerse las deudas no se hizo. No se trata que de esta forma se desconozca que obligación (sic) es una sola o que se incurra en contradicción al sostenerse, por una parte, que la obligación se extinguió y, por la otra, que ella subsiste. Tan solo que debe entenderse que, habiendo varios deudores de la misma, de la insolvencia de uno pueda derivarse la exención de responder al pago que pesa sobre los otros" ${ }^{50}$.

Como apreciamos de la lectura de los fallos antes transcritos, la jurisprudencia no es uniforme acerca de los efectos del descargue sobre las garantías exógenas. El primer fallo citado extiende los efectos del descargue a favor de la obligación del tercero garante (tesis extensiva) atendiendo a la unidad de la obligación de los codeudores solidarios, de modo que extinguida respecto a cualquiera se debería entender extinguida respecto de todos $^{51}$. En cambio, el segundo fallo, en abierta oposición, circunscribe los efectos del descargue de manera exclusiva respecto del deudor insolvente (tesis restrictiva), poniendo el acento en que la responsabilidad del tercero garante está prevista precisamente para el caso que el deudor principal no pague, aunque no ofrece argumentos para sostener esa afirmación.

Habiendo descrito el estado actual de nuestra jurisprudencia sobre el tema de estudio, en los apartados siguientes ofreceremos argumentos para, por una parte, rebatir el planteamiento de la tesis extensiva y, por otra, para fundamentar la tesis restrictiva, tanto desde la perspectiva del derecho civil (2) como concursal (3).

${ }^{50}$ Considerando $2^{\circ}$ de las sentencias pronunciadas por una misma sala de la Corte de Apelaciones de Santiago, Rabobank Chile con Río Teno S.A. y otros (2019a), Rabobank Chile S.A. con Río Teno S.A. (2019b) y Herman con Rabobank (2019).

${ }^{51}$ La afirmación de la sentencia en cuanto a que "la obligación contraída es una sola" parece discurrir sobre el entendimiento que el "fiador y codeudor solidario" queda sujeto frente al acreedor a las reglas de la solidaridad, aunque esa conclusión no es pacífica. Por todos, Corral (2017), especialmente, pp. 216-224. 


\section{Análisis desde la perspectiva del derecho común}

\subsection{La falta de uniformidad de régimen}

de los modos de extinguir las obligaciones

El descargue puede calificarse sin dificultad como un hecho jurídico en virtud del cual desaparece el vínculo que une al deudor y al acreedor, independiente de su satisfacción ${ }^{52}$. Se trata, entonces, de un modo de extinguir las obligaciones -extravagante al listado del art. 1567 del $C C^{53}-$, admitiendo la pregunta de cuan rica en consecuencias es esta calificación. En nuestra opinión, ella contribuye poco a precisar los efectos del descargue debido a las diferencias entre unos y otros modos ${ }^{54}$. Así, por ejemplo, es difícil formular un tratamiento unitario entre aquellos modos satisfactorios y los que no lo son (como la remisión o la confusión), o entre aquellos que suponen la terminación absoluta del vínculo y los que lo reemplazan por uno nuevo (como la novación), o los que permiten su supervivencia (como el pago con subrogación), o entre aquellos que afectan la existencia misma de la obligación y los que solo se refieren a las acciones concedidas para obtener su cumplimiento (como la prescripción) ${ }^{55}$.

Todavía más, una de las principales características que reportan los modos de extinguir no convencionales, es que

"es la ley la que determina la forma en que ellos operan y en que se produce la desvinculación jurídica entre las partes ligadas por la relación obligacional" 56 .

${ }^{52}$ Alessandri et al. (2004), p. 107.

${ }^{53}$ Sin embargo, aludiendo al régimen de la Ley de Quiebras hoy derogada, SANDOvaL (2007), p. 205, entendía: "esta forma de poner término a la quiebra constituye una verdadera prescripción extintiva, cuyo plazo, en este caso, es sólo de dos años, contados desde la aprobación de la cuenta general del síndico". No podemos compartir esta calificación, puesto que la prescripción extintiva se fundamenta en la inactividad del deudor y en una suerte de presunción de pago, y ninguna de estas circunstancias se advierte en el discharge. Por ello, parece más ajustada la explicación de Puelma (1966), p. 205, en el sentido de que este efecto extintivo debe sumarse a los otros modos previstos en el $C C$.

${ }^{54}$ De ahí las necesarias distinciones y subdistinciones que amerita la categoría general de los modos de extinguir las obligaciones, siguiendo el usual modelo propuesto por ALESSANDRi et al. (2004), pp. 109-110, aludiendo a la satisfacción o insatisfacción de la pretensión.

${ }^{55}$ En el mismo sentido se comprenden las distancias entre los modos extintivos convencionales y no convencionales, que constituye la columna vertebral en la tesis de RoDRÍGUEZ (2008), pp. 11-12, caracterizándose estos últimos por no implicar un "provecho económico para el acreedor, quien no obtendrá un beneficio directo proveniente de la extinción de la obligación, como sucede en la mayoría de los modos de extinguir convencionales".

${ }^{56}$ Rodríguez (2008), p. 13. 
De esta manera, el legislador puede modular de manera cabal los alcances de la desaparición, total o parcial, del vínculo obligacional, como ocurre paradigmáticamente con ciertos supuestos de nulidad (absoluta y relativa) o con la prescripción extintiva, en el marco del régimen de las obligaciones naturales previsto en el art. 1470 y ss. del $C C$. Sin embargo, es justo la ausencia de una regulación expresa parte del problema en estudio. En suma, el descargue produce la consecuencia más básica y común a todos los modos de extinguir, cual es liberar al deudor -en ello no hay duda-, pero queda abierta la pregunta sobre los efectos que la regla provoca para terceros, en especial en lo que respecta a los concedentes de las garantías exógenas.

\subsection{La accesoriedad en las garantías exógenas}

Un argumento utilizado para defender la extinción consecuencial de las garantías exógenas una vez producido el descargue de la obligación principal es la accesoriedad (arts. 2381, núm. 3 del $C C$, para la fianza y 2434 del $C C$, para la hipoteca), derivada de la calidad dependiente de las cauciones (arts. 46 y 1442 del CC). Sin embargo, un análisis detenido debilita esa línea de argumentación ${ }^{57}$. Como señala Ramón Domínguez Águila, el principio de accesoriedad

"parece y de hecho así se le califica frecuentemente, como una consecuencia lógica, ineludible e indiscutible, de forma que basta invocarlo para suponer justificada una solución, sin posibilidad de discusión. Sin embargo, nada es tan evidente en ese principio"58.

\section{a) La fianza}

En el ámbito de la fianza, la accesoriedad se manifiesta en varios niveles, al punto de revestir un elemento esencial en su definición (art. 2335 del $C C)$. Dicho carácter se irradia desde la vinculación con la obligación garantizada (art. 2338 del CC), a los límites del contenido de la obligación fideiusoria (arts. 2343, 2344 y $2347 \mathrm{del} C C$ ) y a su extinción (art. $2381 \mathrm{del}$ $C C)$. Esta función vinculante de la accesoriedad impide la creación de una fianza in duriorem causa, ya en términos de onerosidad, ya en cuanto al contenido máximo de la prestación convenida, guardando, al menos, el ideal de reflejo con la obligación principal ${ }^{59}$. Sin embargo, más allá de ello,

${ }^{57}$ Como señala Gómez-Blanes (2019), p. 19: "el régimen jurídico de cada prestación es diverso, dentro de un común denominador. Una obligación accesoria presupone otra principal de la cual depende y a cuyo servicio se pone, pero reviste una multiplicidad de formas y variedades".

${ }^{58}$ Domínguez (2009), p. 41.

${ }^{59}$ Gómez-Blanes (2019), p. 27. 
el principio de accesoriedad no se presenta de manera absoluta, sino flexible, permitiendo, por ejemplo, que la obligación principal no sea siempre susceptible de cobro (arts. 1472, 2338 y 2358, núm. 3 del CC), o que existan supuestos en que el pago de la obligación principal no necesariamente imponga la terminación de sus efectos (art. 1612 del $C C$ ). En suma, bien mirada, la invocación del principio de accesoriedad para precisar los efectos del descargue es poco persuasiva y es necesario analizar otros elementos de la fianza para ofrecer una respuesta al problema en estudio.

La fianza es la única caución (en la triada de los contratos de garantía tratados en el libro IV del $C C$ ) que se refiere de manera expresa a la finalidad de cobertura de la insolvencia (y no solo del incumplimiento) para calificar la idea de seguridad expresada en el art. 46 del $C C$. Al efecto, el art. 2348, núm. 2 del $C C$, dispone que el deudor es obligado a prestar fianza cuando disminuyan sus facultades patrimoniales en términos de poner en peligro manifiesto el cumplimiento de la obligación. A su turno, el art. 2349 del $C C$ establece que si el fiador deviene en insolvente, el deudor deberá prestar nueva fianza. En línea similar, el art. 2365 del $C C$ dispone un estándar de conducta frente al riesgo de insolvencia sobreviniente del deudor una vez opuesto el beneficio de excusión, de manera de limitar la obligación fideiusoria al valor de los bienes excutidos, o a liberarlo de manera más completa si el acreedor tuvo medios suficientes para hacerse pagar y haya sido negligente en servirse de ellos. De estas reglas se concluye que el fiador por lo general toma sobre sí el riesgo de insolvencia del deudor, de manera que la fisonomía natural de la fianza parecería desfigurarse si acaso, por la aplicación del descargue, ella pudiese simplemente desvanecerse, en especial si el acreedor ha sido diligente en la persecución del pago de la deuda.

A mayor abundamiento, dada esta regulación de los efectos de la insolvencia del deudor respecto al fiador, se podrá colegir que se trata éste de un riesgo que concita especial interés para el legislador. Si bien en la mayor parte de los casos podrá afirmarse con certeza que la función de seguridad que ofrece la fianza (como toda otra caución) normalmente se pierde con la extinción de la obligación principal ${ }^{60}$, también se advertirá que la fianza tiene una particular vocación de sobrevivencia en los casos que la extinción consecuencial de la garantía vulnera el propósito de seguridad en vistas al cual se creó ${ }^{61}$. Así podrá ocurrir en los casos en los que el modo de extinguir que haya operado respecto a la obligación principal

${ }^{60}$ Domínguez (2009), p. 44.

${ }^{61}$ Gómez-Blanes (2009), p. 40. Por ejemplo, el art. 21 de la Ley n. ${ }^{\circ} 19496$ dispone que las acciones derivadas de la "garantía legal" podrán hacerse valer, asimismo, indistintamente en contra del fabricante o el importador, en caso de ausencia del vendedor por haber sido sometido a un procedimiento concursal de liquidación. 
deviene como una consecuencia de aquello que la propia garantía pretende asegurar, como se produce en la relación existente entre el discharge y el presupuesto objetivo de los procedimientos concursales. En otras palabras, si la justificación de la normal extinción de la garantía producto de la decadencia de la obligación principal se encuentra en la pérdida de su utilidad $^{62}$, no parece tan simple colegir dicha pérdida si se ha presupuesto que la caución pretende contener los efectos de la insolvencia del deudor.

Precisamente por lo anterior, en nuestra opinión, la determinación de los efectos del descargue sobre una fianza exógena se resuelve atendiendo los mecanismos de defensa que tiene el fiador a quien se le exige el cumplimiento de la obligación fideiusoria, y, en tal sentido, el art. 2354 del $C C$ dispone que el fiador puede oponer cualesquiera excepciones reales, pero no las personales del deudor.

A favor de esta aproximación destaca la referencia a la cesión de bienes (art. 1623 del CC) y al beneficio de competencia (art. 1626, núm. 6 del $C C$ ). Estas medidas excepcionales, derivadas de la única fórmula concursal reglada por la codificación civil, tienen como objetivo premunir al deudor principal de un beneficio que, atendidas sus circunstancias, fijen la esfera de actuación de los acreedores en su patrimonio, pero no en el de los terceros obligados. Ahora bien, aunque pueda sostenerse que la cesión de bienes no provoca la extinción de los saldos insolutos (art. 1619, núm. 2 del $C C$ ), como ocurre con el discharge, aun cabe destacar que ella afecta los parámetros usuales de la accesoriedad de la fianza, mostrando el rasgo de flexibilidad antes aludido. En este sentido, dado que uno de los efectos de la cesión será la obtención del aplazamiento para el cumplimiento de las obligaciones del deudor, articulado a través del beneficio de competencia (art. 1625 del $C C$ ), la regla del art. 1623 del $C C$ deberá entenderse como excepcional a los arts. $1649 \mathrm{del} C C$ (que libera a los fiadores por la ampliación de los plazos) y 2344 del $C C$ (que impide a los fiadores obligarse en términos más gravosos que el deudor principal, entre otros, en relación con el tiempo), de lo que se colige la pretensión del legislador de alterar estos efectos usuales a fin de conservar el vigor de la garantía.

\section{b) La prenda o hipoteca exógena}

Respecto a las garantías reales, el llamativo silencio sobre el destino de la prenda con motivo de la extinción de la obligación principal no podría implicar una consecuencia diversa, en especial si se atiende a las proximidades normativas con la hipoteca, donde tal efecto sí se dispone expresamente (art. $2434 \mathrm{del} C$ C). No obstante, es importante precisar el sentido de la accesoriedad en esta regla, para lo cual es útil distinguir entre el contrato de prenda

${ }^{62}$ Domínguez (2009), pp. 43-44. 
y el derecho real de prenda. Siendo la prenda civil un contrato unilateral y real, la principal obligación que emana del mismo es la que se refiere a la restitución de la cosa prendada por parte del acreedor prendario. De este modo, se entiende que el Código solo se refiera a este aspecto en los primeros incisos de sus arts. 2396 y 2401, aunque solo unido al pago o satisfacción del crédito. Por ello, cosa diversa es la alusión a la accesoriedad del contrato de prenda que se desprende del art. $2385 \mathrm{CC}$ (reiterando el principio del art. 1442 del $C C$ ), puesto que este alude al tiempo de su perfeccionamiento mediante la entrega de la cosa (art. 2386 del $C C$ ), justificando causalmente el título de mera tenencia que importa su constitución ${ }^{63}$. Por su parte, siendo la hipoteca un contrato unilateral y solemne, la obligación que ella genera es la del constituyente, sea el deudor o un tercero, de constituir el derecho real de hipoteca mediante la solicitud y posterior obtención de la inscripción conservatoria. Por ello, el art. 2434 del $C C$ alude a la extinción de la hipoteca, pero como derecho real (en los términos en los que le ha definido el art. $2407 \mathrm{del} C C)^{64}$, y no en referencia al contrato, que, a la sazón, ya se encuentra cumplido. Conforme a estos elementos, la dependencia contractual señalada en el art. 1442 del $C C$ alude al momento genético del título contractual que servirá de causa para la constitución del derecho real de hipoteca, pero no se refiere al destino de este último. Para conocerlo deberemos buscar otras normas al interior del $C C$.

Examinadas las reglas sobre prenda e hipoteca, el destino de la garantía real una vez extinguida la obligación principal presenta un tratamiento fragmentado. Así, por ejemplo, en materia de prenda, la satisfacción de la obligación principal no conlleva el cese de los efectos de la prenda si acaso se cumplen los requisitos de la prenda tácita (art. 2401 del $C C$ ), ni de las prendas o hipotecas cuando se procede a su reserva en la novación (arts. 1642 y 1643 del CC), en los casos del pago con subrogación (art. 1612 del $C C)^{65}$ o en que, declarada la nulidad de la obligación principal, esta devenga en natural (art. 1470, núm. 1 y 1472 del $C C$ ), supuesto en el cual el acreedor no tendrá acción para exigir la cumplimiento de aquella, pero sí la del tercero garante. Fuera del Código, algo similar ocurre con la recién aprobada "portabilidad financiera", puesto que el art. 14 de la Ley n. ${ }^{\circ} 21236$ supone que, aun extinguido el crédito originalmente garantizado por medio de su pago, las cauciones reales no desaparecen, sino que "subsistirán, garantizando de pleno derecho al nuevo crédito,

${ }^{63}$ Aludimos aquí a la posibilidad (o no) de asegurar por medio de la prenda civil el cumplimiento de obligaciones futuras. En este sentido, SOMARRIVA (1943), pp. 216-217 y LECAROS (2009), pp. 21-22. En el caso de la prenda sin desplazamiento, dada la ausencia de cambio en la tenencia del bien, ello se resuelve afirmativa (art. $4^{\circ}$ del art. 14 de la Ley n. ${ }^{\circ} 20190$ ).

${ }^{64}$ Lecaros (2009), p. 401.

${ }^{65}$ Op. cit., pp. 401-402. 
en la totalidad de sus términos y en beneficio del nuevo proveedor"; y, con mayor cercanía, en el art. 98 de la LC, al disponer que la declaración de incumplimiento dejará sin efecto el acuerdo de reorganización, pero no extinguirá las cauciones que hubieren garantizado su ejecución total o parcial, en los términos permitidos en el art. 65 de la LC.

Ante la ausencia de una regla clara acerca de los efectos de la extinción de la obligación principal sobre el derecho real de prenda o hipoteca, es conveniente precisar algunos aspectos del régimen de las garantías reales otorgadas por terceros, como aparece admitida en los arts. 2388 y 2414.II del $C C^{66}$. La idea central de estas reglas puede resumirse del modo siguiente: la posibilidad de que el acreedor cuente con una acción personal para dirigirse en contra del tercero constituyente requiere que este se haya obligado personalmente a la deuda, como ocurrirá en caso de tratarse de un fiador ${ }^{67}$. La regla se coordina con la idea de que la fianza no se presume (art. 2347 del CC). Entonces, a efectos de entender que, además del otorgamiento de la hipoteca, el tercero se ha constituido como fiador, es necesario que así se haya expresado ${ }^{68}$. Solo en tal caso nacerá una acción personal a partir de la obligación fideiusoria.

${ }^{66}$ No debemos entender comprendido en este supuesto el compromiso a título de codeudor solidario o de deudor mancomunado, pues en estos casos no se trataría de la seguridad de una obligación ajena, como exige la primera parte de la regla, sino de una obligación propia.

${ }^{67}$ Estas normas llaman la atención puesto que la primera presupone la existencia de un servicio del tercero a favor del deudor, ajeno al contrato de crédito, mientras la segunda se ubica inmediatamente después de los requisitos de validez de la hipoteca, en lo que se refiere a la capacidad de enajenación. Ahora bien, el referido art. $2414 \mathrm{del} C C$ no solo es indicativo de la posibilidad de otorgamiento de hipoteca para la seguridad de una deuda ajena, sino que tiene por objetivo aclarar el desdoblamiento de las acciones que tendrá el acreedor en caso de incumplimiento de la obligación principal. Así, se deduce que el mentado acreedor por lo general tendrá una acción personal en contra del deudor principal, a menos que se trate de una obligación natural (arts. 1470 y 1472 del CC), pero, por regla general, no gozará de este tipo de acción en contra del tercero constituyente. Lo anterior, a menos que el dueño "se haya sometido expresamente a ella", noción que se reitera en el art. 2430 del $C C$, aunque con una redacción un tanto diversa, al indicar que "no se entenderá obligado personalmente, si no se hubiere estipulado". Este sometimiento no debe entenderse directamente a la acción, a pesar de la mayor proximidad gramatical que se ofrece en la dicción de la regla del art. 2414 del $C C$, sino a la obligación ajena, como resulta aclarado en el tenor del art. 2430 del $C C$. Ello, dado que la acción solo hace referencia al medio de protección jurisdiccional del derecho personal, por lo que no podría entenderse una sujeción a tal acción sin el soporte sustantivo que ella requiere. De ello se sigue que la referencia está dada a la fianza, como se reafirma en la referencia a la "fianza hipotecaria" en el art. 2430.III del $C C$, entendida esta como el caso en que, además de la hipoteca, el deudor se ha constituido en fiador, y diversa a la posibilidad de revestir la obligación fideiusoria con la seguridad de la hipoteca (art. 2344.II del CC).

${ }^{68}$ Sociedad Equipos y Camiones Europeos Limitada con Fidel Pizarro Astorga (2011). 
Sin perjuicio de lo anterior, dada la ausencia de un régimen jurídico completo de la prenda o hipoteca exógena, Manuel Somarriva expresa que existe -en el fondo- una "verdadera fianza, porque en ella el tercero, al igual que el fiador, no tiene interés en la deuda garantizada" ${ }^{69}$. Aunque nos parezca que no pueden extremarse estos conceptos ${ }^{70}$, el autor reproduce la noción de "fianza real" para aludir al caso en que contra el tercero no hay acción personal, sino que el acreedor puede perseguir únicamente el inmueble hipotecado ${ }^{71}$. Para el aspecto que nos interesa, a juicio del citado autor, esta asimilación a la fianza importa ciertas aplicaciones analógicas de su régimen jurídico al caso que tratamos, posibilidad que tampoco descartan quienes niegan el carácter de fiador al tercero garante, en la medida en que no se desnaturalice el régimen de las garantías reales ${ }^{72}$. Al efecto, agrega que se debe reconocer al tercero la posibilidad de ejercicio de la excepción de subrogación, al tiempo que también, si acaso el tercero extingue la deuda y existen fiadores de ella, podrá repetir contra estos de acuerdo con las reglas establecidas para los fiadores ${ }^{73}$. Siguiendo esta línea de argumentación, también podremos observar que no existirían mayores obstáculos para sostener que este tercero no interesado también debería someterse a la distinción de las excepciones reales y personales en lo que respecta a las defensas que puede presentar en el ámbito de la 66 ejecución de la garantía, replicando lo ya indicado respecto a la fianza.

\subsection{La solidaridad}

La construcción de la solidaridad no es idéntica al de las garantías antes estudiadas, puesto que ella no se estructura sobre la base de una obligación accesoria por parte del codeudor solidario, sino desde la idea de la unidad de la prestación (art. 1512 del $C C$ ), sobre la cual, nuestra jurisprudencia, bajo la vigencia de la Ley n. ${ }^{\circ} 18175$, sostuvo la aquí denominada "tesis extensiva" (supra, III. 1) ${ }^{74}$.

${ }^{69}$ SOMARriva (1943), p. 340.

${ }^{70}$ La noción de "fianza real" se justifica en advertir una identidad funcional entre la fianza y las garantías reales de deudas ajenas, pero tropieza especialmente por la necesaria ausencia de la calidad de deudor que tiene el fiador, mas no el constituyente de la prenda o de la hipoteca. Sobre este particular, CARPI (2002), pp. 59-104.

${ }^{71}$ Somarriva (1943), p. 340.

${ }^{72}$ Carpi (2002), pp. 85-86.

${ }^{73}$ Somarriva (1943), p. 340, con cita a doctrina francesa de respaldo (Baudry-Lacantinerie, Aubry y Rau).

${ }^{74}$ Como indicaremos más adelante, la lectura expansiva realizada por la Corte $\mathrm{Su}-$ prema en la sentencia antes referida parece apresurada, incluso en la lógica de la legislación de quiebras derogada, lo que impone la necesidad de revisar de manera más sistemática la órbita en la que cada modo de extinguir opera. 
No obstante, una cosa es que la solidaridad suponga que la cosa debida deba ser idéntica y otra es la que se refiere a que exista una única obligación ${ }^{75}$. Al efecto, como señala Manuel Somarriva Undurraga en referencia al art. 1512 del $C C$ y aludiendo a la pluralidad de vínculos, "en la solidaridad hay tantos vínculos como sean deudores"76. En la misma línea se expresa Luis Claro Solar, al señalar:

"pone este principio de manifiesto que si desde el punto de vista objetivo sólo hay una obligación, desde el punto de vista subjetivo hay tantos vínculos de derecho como deudores o acreedores"77.

Ahora bien, ello no impide que el destino de uno de los tantos vínculos subjetivamente constituidos no tenga efectos respecto a los demás, puesto que, en el fondo, la solidaridad revela la posibilidad de que el acreedor obtenga la prestación de cualquiera de los deudores solidarios (arts. 1511 y 1515 del $C C$ ), de manera que la satisfacción (u otros modos equivalentes al pago) imponen, en principio, la cesación de los efectos obligacionales respecto a todos ellos a fin de evitar un supuesto de enriquecimiento sin causa. Sin embargo, ello no se predica de todos los modos de extinguir las obligaciones, de manera que tampoco encontramos en esta órbita una regla general que permita, sin más, sostener que el efecto del discharge resulta equivalente al que se produce por medio de la extinción por medio del pago (tesis extensiva). Por ejemplo, en el contrato de transacción (art. 1567, núm. 3), conforme a su carácter intuitu personae y del usual efecto relativo de los contratos (art. $1545 \mathrm{del} C C$ ), no produce efectos respecto a los codeudores solidarios, salvo que ella envuelva novación (art. 2461 del $C C$ ), caso en el que de modo excepcional se les liberta a menos que accedan expresamente a la nueva obligación (art. 1519 del $C C$ ). Luego, si la extinción de la obligación se produjo por medio de la declaración de

${ }^{75}$ Para una discusión de este aspecto, tanto en el plano histórico como en la comprensión de la doctrina y jurisprudencia chilena, véase CorRal (2019), p. 54 y Romero (2019), pp. 101-102.

${ }^{76}$ Somarriva (1943), p. 41.

${ }^{77}$ Claro (1936), pp. 369-370. En todo caso, esta idea proviene de Robert Pothier (y, antes que este, de Justiniano y Papiniano), para quien también "l'obligation solidaire est une, á la vérité, par rapport á la chose qui en fait l'objet, le sujet et la matière; mais elle est composée d'autant de liens qu'il y a de personées différentes qui l'ont contractée; et ces personnes étant différentes entre elles, les liens qui les obligent sont autant de liens différents qui peuvent par conséquent avoir des qualités différentes": Pothier (1821), p. 217. [Traducción de los autores: la obligación solidaria es una, en realidad, en relación con la cosa que constituye el objeto, el sujeto y la materia; pero se compone de tantos vínculos como distintas personas lo hayan contratado; y siendo estas personas diferentes entre sí, los vínculos que las obligan son tantos vínculos diferentes que, en consecuencia, pueden tener cualidades diferentes]. 
nulidad (art. 1567, núm. 8, del CC), ella tampoco alcanza a terceros que no hayan comparecido en juicio (art. 1691 del CC), ni necesariamente les afecta en la medida que el vicio puede haber afectado a solo algunas de las relaciones jurídicas, como en supuestos de incapacidad o vicios del consentimiento ${ }^{78}$. Así también, en caso de proceder el evento de la condición resolutoria (art. 1567, núm. 9 del CC), admitida de manera expresa la pluralidad de vínculos (art. 1512 del $C C$ ), ella no afecta a todos los deudores, sino solo a aquellos cuyas obligaciones están sujetas a dicha modalidad. En la prescripción (art. 1567, núm. 10 del CC), ocurre otro tanto, puesto que, a pesar del tratamiento expansivo de la interrupción (art. 2519 del $C C$ ), todo ello depende de si la obligación es exigible para todos los acreedores en igual momento, lo que puede no concurrir si algunas de ellas estén sujetas a modalidad suspensiva (art. 1512 del CC).

El tratamiento diferenciado de los efectos de cada uno de los modos de extinguir las obligaciones frente a los obligados solidariamente impone distinguir, como en la fianza, los medios de defensa que tienen los codeudores solidarios en el ámbito de la obligación a la deuda, en especial si se toma en consideración que el art. 1520.I del $C C$ diferencia entre excepciones reales y excepciones personales. En este sentido, no es efectivo que todos los modo de extinguir se comporten como excepciones reales, lo que alude a todos los casos en que indicamos que, dada la pluralidad de vínculos, es posible que aquello que extingue la obligación respecto a unos, no lo hace respecto a otros.

\subsection{Conclusión parcial}

De todo lo anterior podemos afirmar que, dada la plasticidad del principio de accesoriedad y la ausencia de una regla expresa sobre el efecto del descargue respecto a una garantía exógena, la sola referencia al efecto extintivo del descargue no parece ser lo bastante contundente para concluir la necesaria proyección de sus efectos sobre las garantías exógenas, reales o personales, siendo necesario un análisis coherente con la completa regulación de cada una de esas garantías.

Tampoco resulta siempre cierto que, destruida la eficacia de la obligación respecto de cualquiera de los codeudores solidarios, las consecuencias de dicha extinción deberían extenderse sin más hacia los demás obligados. Ni siquiera podría indicarse que ella comporta la regla general, sino que deberá aludirse a un conjunto de circunstancias adicionales que permiten o no proyectar los efectos extintivos a los demás acreedores.

El examen realizado de las reglas de derecho común sobre garantías y obligaciones solidarias conduce a proponer que la determinación de los

${ }^{78}$ SOMARriva (1943), p. 60. 
efectos del descargue sobre las garantías exógenas deben determinarse conforme al catálogo de las excepciones reales y personales disponible para el tercero garante y que, en el caso particular del descargue, su calificación como excepción real o personal dependerá de su configuración de acuerdo con el derecho concursal, a lo cual destinamos el apartado siguiente.

\section{La lógica concursal}

\subsection{La naturaleza personalísima del descargue}

Como ha quedado indicado antes (supra, I), si bien en sus inicios el discharge aparece como un instrumento al servicio de los acreedores, desde fines del siglo XIX adquirió un marcado carácter tuitivo del deudor insolvente. Las razones para ofrecer esta tutela son de índole económica como humanitaria. Desde una perspectiva económica, un deudor agobiado por las deudas y cuyo patrimonio afecto al concurso ha sido liquidado carece de cualquier incentivo para volver a una actividad productiva, si esas ganancias deben destinarse al pago de los saldos insolutos tras el cierre del concurso. Esta incapacidad financiera ha mostrado ser fuente, a su vez, de problemas alejados de la esfera puramente financiera. Estudios han mostrado cómo una situación de agobio económico afecta no solo a la salud del propio deudor, sino, también, a su entorno familiar, arrojando una correlación positiva entre depresión y sobreendeudamiento, todo lo cual, al fin, se traduce en mayores prestaciones de salud, cuyo prestador (último) es el Estado, con los consiguientes costos individuales y colectivos asociados ${ }^{79}$. También desde la perspectiva de los acreedores es más eficiente eliminar como un crédito incobrable el saldo insoluto tras la realización del patrimonio del deudor afecto al concurso, evitando los costos asociados al monitoreo y, eventual, localización y ejecución de futuros bienes del deudor.

A estas consideraciones económicas se suman aquellas de índole humanitaria, bien presentadas en el Mensaje de la Ley n. 4558 de 1929, cuya idea central conserva plena vigencia:

"es prudente, humanitario y justo no extremar estas medidas [el cobro de las deudas] hasta el exagerado rigor [...]. Muchas veces han sido casualidad y los reveses del destino los que han arrastrado [al fallido] al incumplimiento de sus obligaciones" ${ }^{\prime 0}$.

${ }^{79}$ En Chile, Hojman et al. (2016), pp. 59-61. En la doctrina comparada, CHOI (2009), pp. 121122; Gathergood (2012), p. 1095; Kemelmajer (2008), p. 18 y Sweet et al. (2013), p. 98.

${ }^{80}$ Un texto que, curiosamente, Palma (1940), p. 131 califica de "patético y lloroso". 
El descargue tiene como fundamento permitir al deudor insolvente reiniciar una actividad productiva libre del lastre de sus anteriores deudas (fresh start), generando las condiciones para alcanzar su plena realización material y espiritual (art. $1^{\circ}$ de la Constitución Política de la República), como elementos integrantes del bien común.

Todo lo anterior permite aseverar que el descargue es un beneficio legal estrictamente personal. Este rasgo del descargue aparece recogido de manera positiva al vincularse la extinción a las "obligaciones contraídas por el deudor" (arts. 255 y 268 de la LC). Esta delimitación del ámbito subjetivo del descargue no se ve alterada por establecerse la extinción "para todos los efectos legales", como afirma la primera de dichas normas. Con esa frase no se pretende atender al ámbito subjetivo, ni menos aún extenderlo. Su finalidad es enfatizar, por una parte, la robustez de la tutela concursal a favor del deudor insolvente a efectos de vencer la natural resistencia frente al quiebre de la garantía general patrimonial establecida como idea central de la codificación civil y, por otra parte, que solo quedando el deudor en efecto liberado de los saldos insolutos, estará en condiciones de volver a comenzar su actividad productiva o de consumo, según el caso.

El carácter personalísimo del descargue permite aclarar, en sede concursal, cuál debe ser el efecto del mismo sobre las garantías exógenas. Los terceros no son beneficiados con el descargue, pues ellos no han estado sujetos a un procedimiento concursal de liquidación (ni de renegociación). Por supuesto, nada impide que el tercero garante también pueda ser beneficiario de la extinción legal de los saldos insolutos de sus propias deudas, pero para ello es imprescindible que se encuentre insolvente y haya terminado, por sentencia firme, el respectivo procedimiento concursal. Solo en esas circunstancias ese tercero garante será merecedor de esta intensa tutela concursal, pero, mientras ello no suceda, no parece razonable que un tercero solvente pretenda inmerecidamente verse favorecido con la extinción de sus propias obligaciones.

\subsection{El descargue como excepción personal}

ante el derecho común

Como ha quedado indicado previamente (II), los efectos del descargue respecto del tercero garante dependen de la calificación de ese modo de extinguir las obligaciones como una excepción real o personal. Si el descargue es calificado como una excepción real, el tercero garante podrá aprovecharse de los efectos de la resolución de término firme en el procedimiento concursal de liquidación del deudor o de los efectos del acuerdo de ejecución, liberándose también del cumplimiento de su obligación. En cambio, si el descargue constituye una excepción personal, la extinción 
de los saldos insolutos solamente debe aprovechar al sujeto a favor de quien se establece, siendo exigible al tercero garante el cumplimiento de la prestación garantizada.

Las excepciones reales son aquellas "que por su naturaleza son inseparables de ésta [la obligación principal]"; en cambio, las excepciones personales son "las que se basan en situaciones particulares del obligado $y$, por ende, sólo puede oponerlas el obligado en que ellas concurren" ${ }^{\text {. }}$. Así, por ejemplo, el pago, la novación, la pérdida fortuita de la cosa son excepciones reales. A su turno, la cesión de bienes, el beneficio de inventario y la transacción son excepciones personales ${ }^{82}$.

El descargue, según antes hemos explicado, es un beneficio legal personalísimo y, por consiguiente, no debe considerarse como una circunstancia "inherente a la obligación principal". Se trata de una situación particular del deudor insolvente, debiendo calificarse como una excepción personal. Esto significa que una vez firme la resolución de término de un procedimiento concursal, si un acreedor quisiera exigir el pago del saldo insoluto de una obligación nacida con anterioridad al inicio del procedimiento concursal, el deudor puede oponerle la excepción de descargue, enervando la acción de cobro.

La situación es distinta en el caso del tercero garante. Si un acreedor quisiera ejecutar la garantía exógena para cobrar un crédito insoluto tras quedar ejecutoriada la resolución de término de un procedimiento concursal de liquidación, el tercero garante no puede invocar a su favor el descargue, pues no se trata de una excepción real, sino personal (del deudor insolvente).

${ }^{81}$ Vodanovic (1999, reimpresión 2004), p. 143. En el mismo sentido, Somarriva (1943), p. 69 y Peñallillo (2013), pp. 290 y 292.

${ }^{82}$ Sin embargo, la aparente claridad de la distinción da paso a la incertidumbre frente a otras excepciones. Así, por ejemplo, el dolo y la fuerza son vicios del consentimiento calificadas como excepciones reales en la fianza (art. 2354 del $C C$.) Esto ha generado críticas. René Abeliuk justifica esta calificación en la mayor dependencia del vínculo entre fiador y deudor, pero no se considera aplicable esa calificación en la solidaridad: ABELIUK,

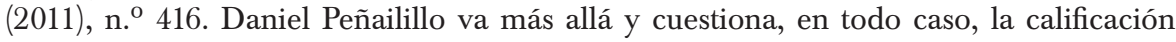
del dolo y la fuerza como excepción real, pues "son defectos subjetivos (aunque deban evaluarse objetivamente), individuales, que padece cierta persona, de modo que en rigor son netamente excepciones personales": PEÑAILILlo (2013), p. 292. Aun cuando no podamos ocuparnos aquí de esta cuestión, al menos cabe enunciar que la clasificación entre excepciones personales y reales "no suministra ningún criterio sustantivo con arreglo al cual pueda averiguarse si una determinada excepción es oponible o inoponible y que en este último caso permita establecer cuáles son las condiciones de su eventual oponibilidad": PaZ-Ares (1985), p. 686. 


\section{Conclusiones}

A lo largo de este trabajo, hemos podido constatar que, a pesar de las influencias anglosajonas en su primer reconocimiento legal, el tratamiento jurídico del discharge en el ordenamiento chileno ha sido impreciso e incompleto. Algo que pasó bastante desapercibido en las leyes de quiebra, probablemente por tratarse de una solución residual, constituye hoy el centro de atención al disponerse como la principal consecuencia legal del término de los procedimientos liquidatorios. Más allá de la ausencia de requisitos y limitaciones, también llama la atención la falta de referencia a los efectos que ella produce en las garantías exógenas, lo que ha suscitado nuevos debates, tensionando las lógicas concursales con las normas del derecho común.

La coordinación entre las normas del derecho común y las concursales suele resolverse conforme al criterio de especialidad, primando estas sobre aquellas. Sin embargo, ante la ausencia de una regla concursal expresa para zanjar el efecto del descargue sobre las garantías exógenas es necesario aguzar la mirada para comprender cómo el derecho común debe ajustarse al régimen especial. En nuestro caso, esa operación tiene como criterio basal el carácter personalísimo del descargue en la legislación concursal a favor del deudor insolvente, a fin de permitirle reinsertarse en la actividad productiva y así disponer de los medios para su pleno desarrollo personal.

Desde la óptica del derecho común, el descargue produce una profunda fisura en el modelo de responsabilidad patrimonial del deudor al limitar la garantía general patrimonial a los bienes presentes y excluir los futuros. Esa alteración del régimen común se ha pretendido entender también como un beneficio que alcanza las garantías exógenas, extinguiéndolas (tesis extensiva). Sin embargo, esa lectura no solo se aparta de la lógica concursal del descargue, sino que desconoce el tratamiento diferenciado de la obligación caucionada y las garantías que el propio $C C$ ofrece para supuestos similares. Ese régimen bifronte del derecho común se articula teniendo en consideración que el descargue, en cuanto modo de extinguir las obligaciones de carácter personalísimo, solo puede operar como una excepción personal a favor del deudor insolvente y no como una excepción real a favor de todos los obligados en garantía.

\section{Bibliografía CITADA}

Abeliuk, René (2011). Las obligaciones. $5^{\text {a }}$ ed. Santiago: Editorial Jurídica de Chile, tomo I.

Alarcón CAÑutA, Miguel (2018a). "La deuda por obligación constituida a través de crédito con aval del estado no constituye excepción al discharge en el ordenamiento jurídico chileno". Revista Chilena de Derecho Privado, n. ${ }^{\circ} 31$. Santiago. 
Alarcón Cañuta, Miguel (2018b). "Comentarios críticos al fresh start en el concurso de la persona natural de la Ley $\mathrm{N}^{\circ} 20.720$ desde la perspectiva dogmática comparada”, en Lorena Carvajal Arenas y Ángela Toso Milos. Estudios de derecho comercial. Octavas Jornadas Chilenas de Derecho Comercial. Santiago: Editorial Thomson Reuters.

Alessandri Rodríguez, Arturo, Manuel Somarriva Undurraga y Antonio VoDanovic Haklicka (2004). Tratado de las obligaciones. Santiago: Editorial Jurídica de Chile.

Araya Paredes, Ignacio y Octavio Bofill Genzsch (2013). "Análisis y comentarios a la reforma al régimen concursal chileno (Boletín $\mathrm{N}^{\circ}$ 8324-03)". Revista de Derecho. Escuela de Postgrado, n. ${ }^{\circ}$ 4. Santiago.

Arcos Riveros, Blanca (1929). De las quiebras en nuestro derecho. Santiago: Soc. Imprenta y Lit. Universo.

Bravo Rodríguez, Armando (1940). El sobreseimiento en las quiebras. Santiago: Imp. Benaprés y Fernández Limitada.

Caballero Germain, Guillermo (2015). "El presupuesto objetivo del concurso", en Guillermo Caballero Germain y Osvaldo Lagos Villarreal (coords.). Estudios de derecho comercial. Quintas jornadas chilenas de Derecho comercial. Santiago: Editorial LegalPublishing.

Caballero Germain, Guillermo (2017). "Comentario de jurisprudencia. La exclusión de un crédito del procedimiento concursal de una empresa deudora”. Revista Chilena de Derecho Privado, n. ${ }^{o}$ 29. Santiago.

Caballero Germain, Guillermo (2018). "Sobreendeudamiento y exoneración legal de los saldos insolutos en el procedimiento concursal del consumidor". Ius et Praxis, vol. 24, n. ${ }^{\circ}$ 3. Talca.

Caballero Germain, Guillermo (2020). "El crédito con aval del estado y la exoneración legal de los saldos insolutos en un procedimiento de liquidación concursal", en Hugo Cárdenas (ed.). Jurisprudencia crítica. Comentarios de fallos 2018. Santiago: Rubicón.

CARPi Martí, Rebeca (2002). La hipoteca en garantía de deuda ajena. Madrid: Editorial Centro de Estudios Registrales.

Carrasco Perera, Ángel (2008). Los derechos de garantía en la Ley concursal, $2^{\mathrm{a}}$ ed. Cizur Menor: Editorial Thomson Civitas.

Carrasco VÁsquez, Jorge (1963). Evolución del derecho de quiebras en Chile. Santiago: Editorial Jurídica de Chile.

Chor, Laura (2009). "Financial stress and its physical effects on individuals and communities". Community Development Investment Review, vol. 5, issue 3. San Francisco.

Claro Solar, Luis (1936). Explicaciones de Derecho civil chileno y comparado, vol. v: De las obligaciones. Santiago: Editorial Nascimento.

Contador Rosales, Nelson y Cristián Palacios Vergara (2015). Procedimientos concursales. Santiago: Editorial Thomson Reuters. 
Corral Talciani, Hernán (2016). "El nuevo régimen concursal: notas sobre su impacto en materias de Derecho civil", en Eduardo Jequier (ed.). Estudios de derecho concursal. La Ley $N^{\circ} 20.720$, a un año de su entrada en vigencia. Santiago: Editorial Thomson Reuters.

Corral Talciani, Hernán (2017). "Se obliga como fiador y codeudor solidario: revisión del alcance de una cláusula usual en la contratación chilena”, en Hernán Corral Talciani y Pablo Manterola Domínguez (eds.). Estudios de derecho civil XII. Santiago: Editorial Thomson Reuters.

Corral Talciani, Hernán (2019). "Nuevas tendencias en la comprensión y funcionamiento de la obligación solidaria”, en Hernán CORRAL y Alejandro Romero. Solidaridad obligacional. Diez estudios sobre sus aspectos civiles y procesales. Valencia: Editorial Tirant lo Blanch.

Domínguez Águila, Ramón (2009). "El principio de lo accesorio y la prescripción de las acciones de garantía", en Mauricio TAPIA Rodríguez et al. Estudios sobre garantías personales y reales. Libro homenaje al profesor Manuel Somarriva Undurraga. Santiago: Editorial Jurídica de Chile, tomo I.

Durán Bernales, Alberto (1935). Explicaciones y jurisprudencia de la Ley de Quiebras de Chile. Santiago: Talleres Gráficos Gutenberg.

FERnÁNDEZ, Leonardo F. (2009). "La causa-fin en las garantías personales”, en Mauricio TAPIA RoDRÍGUEZ et al. Estudios sobre garantías personales y reales. Libro homenaje al profesor Manuel Somarriva Undurraga. Santiago: Editorial Jurídica de Chile, tomo I.

Gathergood, John (2012). "Debt and Depression: causal links and social norm effects". The Economic Journal, vol. 122. Disponible en http://onlinelibrary. wiley.com/doi/10.1111/j.1468-0297.2012.02519.x/pdf [fecha de consulta: 22 de julio de 2017].

Goldenberg Serrano, Juan Luis (2017). "La responsabilidad patrimonial universal y el sobreendeudamiento de la persona deudora”, en Hernán CORRAL y Pablo Manterola (eds.). Estudios de derecho civil XII. Santiago: Editorial Thomson Reuters.

Goldenberg Serrano, Juan Luis (2019). “¿Existe un deber del deudor de conocer e informar su situación de insolvencia al tiempo de contratar?". Revista de Derecho, vol. XXXII, n. ${ }^{\circ}$ 2. Valdivia.

Goldenberg Serrano, Juan Luis (2020). "El origen y la evolución de la extinción del saldo insoluto como resultado del concurso en el discurso anglosajón y su incorporación en la legislación chilena de quiebras de 1929". Revista Chilena de Derecho, vol. 47, n. ${ }^{\circ}$ 2. Santiago.

Goldenberg Serrano, Juan Luis (2020a). "El sobreendeudamiento y los paradigmas del consumidor financiero responsable y del proveedor financiero profesional”. Ius et Praxis, vol. 26, n. ${ }^{\circ} 1$. Talca.

Gómez Balmaceda, Rafael y Gonzalo Eyzaguirre Smart (2011). El derecho de quiebras, $2^{\mathrm{a}}$ ed. aumentada. Santiago: Editorial Jurídica de Chile, tomo II. 
Gómez-Blanes, Pablo (2009). "La accesoriedad de la fianza". Vniversitas, n. ${ }^{\circ} 118$. Bogotá.

Gross, Karen (1999). Failure and forgiveness. New Haven/London: Yale University Press.

Hojman, Daniel, Álvaro Miranda \& Jaime Ruiz-Tagle (2016): "Debt trajectories and mental health". Social Science \& Medicine, vol. 167. Disponible en http:// repositorio.uchile.cl/bitstream/handle/2250/143256/Debt-trajectories-andmental-health.pdf? sequence $=1 \&$ is Allowed $=y$ [fecha de consulta: 21 de julio de 2020].

Jackson, Thomas H. (1986). The logic and limits of bankruptcy law. Cambridge, Massachusetts: Harvard University Press.

JeQuier Lehuedé, Eduardo (2015). "Nuevas tendencias para la reorganización de empresas insolventes en la legislación chilena: estatuto jurídico de los acreedores hipotecarios y prendarios en el procedimiento de reorganización judicial preventivo", en Camilo Martinez Blanco (coord.). Estudios de derecho concursal uruguayo. Montevideo: Universidad de Montevideo, vol. II.

JEQUiER LeHuedé, Eduardo (2016). "Nuevas tendencias para la reorganización de empresas insolventes en la legislación chilena”, en Eduardo JEQUIER (ed.). Estudios de derecho concursal. La Ley $N^{\circ} 20.720$, a un año de su entrada en vigencia. Santiago: Editorial Thomson Reuters.

Kadens, Emily (2010). "The last bankrupt hanged: balancing incentives in the development of bankruptcy law". Duke Law Journal, vol. 59, No. 7. Durham.

Kemelmajer, Aída (2008). "El "sobreendeudamiento" del consumidor y la respuesta del legislador francés”. Anales, n. ${ }^{\circ} 46$. Buenos Aires, La Ley-Academia Nacional de Derecho y Ciencias Sociales de Buenos Aires.

Lecaros Sánchez, José Miguel (2009). Las cauciones reales. Prenda e hipoteca. $2^{\mathrm{a}}$ ed. Santiago: Editorial Metropolitana.

MCCoID, John (1996). "Discharge: the most important development in bankruptcy history”. American Bankruptcy Law Journal, vol. 70, No. 2. United States of America.

Noel, F. Regis (1919). A history of bankruptcy law. Washington D.C: Chas. H. Potter \& Co.

Palma Rogers, Gabriel (1940). Legislación de quiebras. Explicación de sus clases redactadas por Gustavo Cid C. Santiago: Talleres Gráficos Samaniego.

PAZ-Ares, José Cándido (1985). "El sistema de las excepciones cambiarias". Revista de Derecho Mercantil, n. ${ }^{\circ}$ 78. Cizur Menor.

Peñailillo Arévalo, Daniel (2013). Las obligaciones. Santiago: Editorial Jurídica de Chile.

Pothier, Robert Joseph (1821). Ouvres complètes. Traité des obligations. Paris: Thomine et Fortic, Libraires, tome I.

Puelma AcCorsi, Álvaro (1966). Curso de derecho de quiebras. Santiago: Editorial Jurídica de Chile. 
Puga Vial, Juan Esteban (2004). Derecho concursal. El juicio de quiebras, $3^{\mathrm{a}}$ ed. actualizada. Santiago: Editorial Jurídica de Chile, tomo II.

Puga Vial, Juan Esteban (2014). El acuerdo de reorganización. Santiago: Editorial Jurídica de Chile.

Puga Vial, Juan Esteban (2016). "Mirada crítica de la Ley N²0.720”, en Eduardo JEQUiER (ed.). Estudios de derecho concursal. La Ley $N^{\circ} 20.720$, a un año de su entrada en vigencia. Santiago: Editorial Thomson Reuters.

Rodríguez Grez, Pablo (2008). Extinción no convencional de las obligaciones. Santiago: Editorial Jurídica de Chile, vol. 2.

Romero Seguel, Alejandro (2019). "La naturaleza jurídica de la obligación solidaria y su proyección procesal”, en Hernán CorRal y Alejandro Romero. Solidaridad obligacional. Diez estudios sobre sus aspectos civiles y procesales. Valencia: Editorial Tirant lo Blanch.

Ruz LÁrtiga, Gonzalo (2017). Nuevo derecho concursal. Santiago: Editorial Thomson Reuters, tomo I.

Sandoval LóPez, Ricardo (2007). Derecho comercial, $6^{\text {a }}$ ed. actualizada. Santiago: Editorial Jurídica de Chile, tomo Iv: La insolvencia de la empresa. Derecho concursal: quiebras, convenios y cesiones de bienes.

Somarriva Undurraga, Manuel (1943). Tratado de las cauciones. Santiago: Editorial Nascimento.

76 Sweet, Elizabeth, Arijit NAndi, Emma Adam \& Thomas McDade (2013). "The high price of debt: Household financial debt and its impact on mental and physical health". Social Science \& Medicine, vol. 91. Disponible en www.sciencedirect.com/science/article/pii/S0277953613002839 [fecha de consulta: 22 de julio de 2020].

Vodanovic Haklicka, Antonio (1999, reimpresión 2004). La fianza. Santiago: Editorial LexisNexis.

Zimmermann, Reinhard (1996). The Law of Obligations. Oxford: Oxford University Press.

\section{Jurisprudencia citada}

Banco de Concepción con Manuel Arredondo y otro (1992): Corte Suprema, 16 de enero de 1992, recurso de queja, en Gaceta Jurídica. n. ${ }^{\circ}$ 141, Santiago, 1992.

Sociedad Equipos y Camiones Europeos Limitada con Fidel Pizarro Astorga (2011): Corte Suprema, 3 de enero de 2011, casación en la forma, Westlaw CL/JUR/ 6099/2011.

Loreto Ried Undurraga con Gonzalo Baeza Ovalle (2012): Corte Suprema, 27 de marzo de 2012, casación, Westlaw CL/JUR/743/2012.

Rabobank Chile con Río Teno (2019a): Corte de Apelaciones de Santiago, 30 de enero de 2019, apelación, rol n. ${ }^{\circ}$ 12.247-2017. Disponible en www.pjud.cl [fecha de consulta: 21 de julio de 2020]. 
Rabobank Chile con Río Teno (2019b): Corte de Apelaciones de Santiago, 30 de enero de 2019, apelación, rol n. ${ }^{\circ}$ 12.841-2017. Disponible en www.pjud.cl [fecha de consulta: 22 de julio de 2020].

Rabobank Chile con Río Teno S.A. y otros (2019c): Primera Sala de la E. Corte Suprema, 27 de noviembre de 2019, casación, rol no 12649-2019. Disponible en www.pjud.cl [fecha de consulta: 21 de julio de 2020].

Herman con Rabobank (2019): Corte de Apelaciones de Santiago, 30 de enero de 2019, apelación, rol C-13370-2017. Disponible en www.pjud.cl [fecha de consulta: 21 de julio de 2017].

Javiera Mancilla Oyarzo con Tesorería General de la República (2020): Corte Suprema, 20 de julio de 2020, recurso de protección, rol n. ${ }^{\circ}$ 59567-2020. Disponible en www.pjud.cl [fecha de consulta: 22 de julio de 2020].

SiglaS y ABREVIATURAS

$\begin{aligned} \text { al. } & \text { alii (otros) } \\ \text { art. } & \text { artículo } \\ \text { arts. } & \text { artículos } \\ \mathrm{c} . & \text { chapter } \\ \mathrm{CAE} & \text { Crédito con Garantía Estatal } \\ C C & \text { Código Civil }\end{aligned}$

CNUDMI Comisión de las Naciones Unidas para el Derecho Mercantil Internacional

Co. Company

coord. coordinador

coords. coordinadores

D.C. Distrito de Columbia

E. Excelentísima

ed. editor a veces edición

eds. editores

http Hypertext Transfer Protocol

LC o Ley Concursal Ley n. ${ }^{\circ}$ 20720, de 2014

Lit. Litografía

n. ${ }^{\circ}$ a veces núm., No. número

núms. números

op. cit. opere citato (obra citada)

p. página

pp. páginas

Soc. Sociedad

ss. siguientes

vol. volumen

www. World Wide Web 